\title{
EXAMINING FLEXIBILITY IN SPACE USE IN ARCHITECTURAL DESIGNS OF PUBLIC CORE HOUSING SCHEMES IN ANAMBRA STATE OF NIGERIA
}

\section{Dr. Nnaemeka Bennet Christian Dillon Okoye ${ }^{1}$, Prof. Ikechukwu Onyegiri ${ }^{3}$ and Dr. Marcellinus Okafor ${ }^{2}$}
${ }^{1}$ Department of Architecture, School of Environmental Design and Technology, Federal Polytechnic Oko, Nigeria E-mail: emii2him@gmail.com
${ }^{2}$ Department of Architecture, Faculty of Environmental Sciences, Imo State University, Owerri, Nigeria
E-mail: onyegiriikechukwu@gmail.com
${ }^{3}$ Department of Architecture, Faculty of Environmental Sciences, Imo State University, Owerri, Nigeria
E-mail: arcdrmuokafor@gmail.com

\section{Cite this article:}

Okoye N.B.C.D. , Onyegiri I., Okafor M. (2021), Examining Flexibility in Space Use in Architectural Designs of Public Core Housing Schemes in Anambra State of Nigeria. African Journal of Economics and Sustainable Development 4(2), 39-85. DOI:

10.52589/AJESDKHHYLSIW.

\section{Manuscript History \\ Received: 11 June 2021 \\ Accepted: 9 July 2021 \\ Published: 24 July 2021}

Copyright $\odot 2020$ The Author(s) This is an Open Access article distributed under the terms of Creative Commons AttributionNonCommercial-NoDerivatives 4.0 International (CC BY-NC-ND 4.0 ), which permits anyone to

share, use, reproduce and redistribute in any medium, provided the original author and source are credited.
ABSTRACT: Studies indicate flexibility in space use in architectural design as enhancing core housing affordability. Despite this and the notion that intended residents cannot afford core houses, it is not yet documented what constitutes this attribute, and whether they featured in the core house designs. This information, required as a check for future designs, is lacking. Study examined flexibility in space use in architectural designs of existing public core housing schemes in Anambra State, Nigeria, using Mixed Method approach (data sourced from architectural drawings of existing prototypes, field observations and personal interview protocols). Observation schedule with "Yes" and "No" ratings was used in ascertaining reflection of the attribute in each of the 7 prototypes studied. The attribute was found featuring only in 1 out of the 7 prototypes. For affordability improvement, the paper recommends consideration of the variables constituting flexibility in space use in future core housing designs in Anambra State.

KEYWORDS: Architectural design characteristics, Flexibility in space use, Housing affordability, Core housing schemes, Low-cost housing. 


\section{INTRODUCTION}

The provision of adequate housing has been reckoned with enormous challenges, central to which is the affordability issue. In view of the adverse conditions being experienced globally as a result of the dearth of affordable housing, it has remained a key area of concern. As such this subject has received much attention in global housing summits such as the 1992 Rio-de Janeiro summit on environment and development, the 1996 Habitat summit at Istanbul, the 2000 New York, United Nations Millennium Development Goals (MDGS) summit, the 2002 World Summit in Johannesburg and the 2005 La Havana, UN Sustainable Cities Documentation of Experience Programme (Ugonabo \& Emoh, 2013).

Alongside various efforts at solving global housing affordability problems, one of the strategies known to have evolved in this area is the concept of Core housing. Core housing has been an alternative strategy to the provision of the conventional whole house types and is initiated to deliver low-cost housing to the teeming population of low-income urban dwellers. Abrams (1964) put it that core housing is a low-cost housing delivery strategy intended for households who cannot afford whole houses (full-provision/finished), due to their lean income disposition. The intent of this strategy is the provision of a small unit of habitable housing, known as the core house, which is meant to portray flexibility in the use of the minimal space provided, with the potential for easy futuristic expansion. The essence of this is to design the small space being provided in a multi-purpose (multi-functional) fashion for it to cater for various uses. By so doing, the need for extra spaces to accommodate those functions is eliminated.

Consequently, in order to make the elimination of various dedicated and functional spaces viable, care should be taken in design to ensure that the multi-purpose potential of the provided core unit is not compromised. It is the achievement and advantage of this that actually gives meaning to the possibility of having a minimal unit at the inception; which performs the basic functions of several other spaces in a contemporary house type. The multipurpose space is done in such a way that it is capable of meeting different requirements that run concurrently. Therefore the essence of the attribute "flexibility in space use in architectural design" is to make the reduction of the initial habitable space possible. The reduction of initial space requirement itself invariably results in bringing down the house price of the initial habitable unit and hence its affordability.

Good as flexibility in space use in architectural design as an attribute is in fostering affordability of core houses, it has been observed that the design of several prototypes developed appear to have neglected this pertinent design consideration. Provision of separate and dedicated spaces for varying functions that should have been incorporated in the multipurpose space appear to have been in vogue. The result of this compromise in design is the proliferation of initial core houses that appear more as full-provision and finished houses than partial and minimal. A situation where a 3-bedroom apartment, for instance, has been designed as a core house meant to obviate the harsh housing affordability conditions prevailent for the low-income people in the urban setting obviously needs to be checked. It is doubtful if such housing will be able to meet up as affordable solution for the intended residents. Such housing schemes are likey to end up benefitting the higher income households who are able to afford whole houses, and therefore have no need for the partial provision alternative. 
Several studies: Ike (1996), Greden (2005), Association of Collegiate Schools of Architecture (ACSA) (2006); Emamgholi (2011) and Adulpader, Sobah \& Abdullah (2014) have explained the meaning of flexibility in space use in architectural design and it has been noted how it positively influences core housing affordability. However, the design considerations that make up flexibility in space use in architectural designs of core houses have not been clearly documented such that designers would know what to look out for in making their designs compliant to this attribute. Similarly, not much has been documented on whether the various core houses developed have reflected flexibility in space use in their architectural designs. As such design professionals have been left without information on how the prototypes developed performed in the inclusion of this characteristic in their designs. The lack of information on the design considerations that make up flexibility in space use in architectural design and how it featured in the existing core housing schemes has made it difficult to know what things to be mindful of in the design of future core housing schemes. The critical need of these informations imanates from the relevance of flexibility in space use in architectural design in promoting core housing affordability. This scenario seems to be the case in Anambra State of Nigeria. There is lack of information on what constitutes flexibility in space use in architectural design as it relates to core housing affordability, and whether it has been duly considered in the architectural designs of public core houses in Anambra State of Nigeria; because such a study has so far not been documented. This study investigated this phenomenon in Anambra State of Nigeria by examining the existing public core housing schemes to know if flexibility in space use in architectural design as an attribute is reflected in the prototypes.

To achieve this, the following objectives were pursued, and they were meant to:

i) Review literature explaining what constitutes flexibility in space use in architectural design in relation to core housing affordability; and

ii) Ascertain if flexibility in space use is reflected in the architectural designs of the existing public core housing schemes in Anambra State.

In order to realize these objectives, the following research questions were pursued:

1. What constitutes flexibility in space use in architectural design in relation to core housing affordability?

2. Is flexibility in space use reflected in the architectural designs of the existing public core housing schemes in Anambra State?

\section{LITERATURE/THEORETICAL UNDERPINING}

\section{Core Housing}

Core housing is an attempt at providing low-cost partial-provision habitable housing that serves as an alternative to the conventional full-provision type. Several studies: Abrams (1964); Napier (2002); Pandelaki and Shiozaki (2010); Goethert (2010); and Maly and Tamyo (2012) have portrayed core housing essentially as a partial but permanent structure professionally designed to be minimal in size and incomplete but habitable initially, having 
the potential for incremental upgrading. The upgrading is as the need occurs and resources are available. Greene and Rojas (2008) note that the deficiencies of the full-provision house types in affordability, the low-income disposition of households, coupled with the nonavailability of mortgage financing in housing provision for them necessitated the originating of the core housing strategy. Globally core housing is conceived as an affordable housing solution for households who cannot afford the conventional whole houses because of their lean income status (Abrams, 1964; Napier, 2002; Greene \& Rojas, 2008; Pandelaki \& Shiozaki, 2010). According to Goethert (2010), core houses begin as starter core shelters, in form of multi-purpose rooms or studio apartments, with basic kitchen/bath facilities adding that the owners are expected to control the expansion based on their needs and resources.

\section{Housing Affordability}

Housing affordability is basically seen as a measure of the extent to which housing price for a given standard of housing affects a household's "income to live on", or their capacity to meet their total household need (Hancock, 1993 cited in Milligan, 2003). Aput in another way, housing affordability, according to Sharipah and Sidi (2011), is a measure of the proportion between what households earn and what they pay for their housing, and the cost of house against the amount buyers can afford. Mutisya (2015) observes that housing financing is usually either through personal savings or mortgage financing, while Breimer (2011) notes that majority of low-income households hardly have access to mortgage loans. What is therefore applicable in matters of their housing acquisition method and affordability is that obtained through personal savings. Gudeta (2010) and Breimer (2011) report that "house price to income ratio" is considered as a common measure of affordability for houses acquired through personal savings. The ratio is expressed thus: house price should not exceed $2^{1 / 2}$ (2.5) times of household's annual income or 30 times of the household's average monthly income (Grimmes, 1976; Feins and Lane, 1981 cited in Ndubueze, 2009). According to Okoye, Onyegiri and Okafor (2021), a house which is acquired through personal savings would then be said to be affordable if house price (HP) $<$ or $=2.5 \mathrm{x}$ household's average annual income (HAAI) or $30 \mathrm{x}$ household's average monthly income (30 x HAMI or 30HAMI). For this type of housing, affordability measure can as such be viewed as the relationship between HP and 2.5 HAAI or 30HAMI. Since core housing is targeted at households who cannot afford whole houses, those of them whose " $2 \frac{1}{2}$ times average annual income" are less than or equal to the price of the least of the whole house types in a place therefore constitute the intended beneficiaries of core housing (Okoye, Onyegiri \& Okafor, 2021). The implication is that core houses should be delivered at prices lower than the price of the least of the whole house types in a place in order to justify it as an affordable alternative to those who cannot afford whole houses.

\section{Objective 1 - Review literature explaining what constitutes flexibility in space use in architectural design in relation to core housing affordability}

Design flexibility in space use in architectural design concerns measures put in place at the design stage of a building in order to achieve unstructured multi-functional (multi-purpose) space(s) having the potentyial to take care of various concurrent activities. The space could be designed in a way that it operates varied, or multiple functions. Distinct activities could be separated when required through demountable partitions and sliding furnitures. This design attribute helps in ensuring the achievement of optimal utilization of spaces and minimizing the occurrence of dormancy of spaces. In line with this, Esenwein (2016) observes that in the 
second half of the $19^{\text {th }}$ century, domestic architecture adopted the utilization of the open plan (one that had a single room for multiple functions). Adulpader, Sobah and Abdullah (2014) opine that flexibility in space use helps in offering architectural solutions towards maximizing benefits and functional uses of spaces. This is with the result that hardly any space is left dormant or inactive through the various activity times of the day morning, afternoon, evening or night. Such spaces are designed for multi-purpose activities at inception, and simply by the use of furniture one could utilize space without any further general modifications (Adulpader, Sobah \& Abdullah, 2014). Similarly, Emamgholi (2011) reckons that flexibility in space use in architectural design could be achieved by creating multi-purpose spaces which are capable of meeting different use requirements; and by change of furniture type one could utilize space appropriately without any modifications.

Studies describing the architectural design characteristics that aid in improving affordability of core housing reveal that, being a low-cost housing strategy, it rests on the basis of devicing a minimally acceptable (small) initial house built with inexpensive building materials. This depicts simplicity in design (Ike, 1996; Napier (2002); Pandelaki \& Shiozaki, 2010; Maly \& Tamyo, 2012; Atamewan \& Olagunju (2017). This initial minimal house ought to be flexible in space usage; portraying flexibility in space use in architectural design (Ike, 1996; Greden, 2005). The house should also have the characteristics that make it easily adaptable for expansion; hence showing adaptability in expansion (Gorglewski, 2005; Schmidt III, Eguchi, Austin \& Gibb 2010). Also it should have qualities that lower financial resources expended in land acquisition, hence lower dwelling lot value (Dewar, 2009; Pandelaki and Shiozaki, 2010; Breimer, 2011; Woetzel, Ram, Mischke, Garemo and Sankhe, 2014).

Studies also abound showing that flexibility in space use in architectural design use promotes affordability of core housing. In the study on affordable homes as a guide to easy homebuilding, Ike (1996) observed that it avails prospect for the starter unit (core house) to maintain the elastic multi-purpose use of sleeping, sitting and dining may later translate into a kitchen or bedroom after future expansion. By so doing, allowance is made by design for flexibility to a wide range of users' needs, which translates to optimal use of available space. Since less amount of space is required to perform several functions, price of initial house by design is reduced. The achievement is the development of a compact multi-functional house which has the potential for expansion as increase of family size and or resources occur. The study recommends that the sitting room and kitchen can also be used for dining and for food storage respectively, instead of providing additional spaces for them; wall and ceiling areas could be taken advantage of for storage in a multi-functional studio apartment, instead of providing a separate space for storage, because of its cost advantage.

Likewise, in the study on affordable design, Association of Collegiate Schools of Architecture, ACSA, (2006) found that flexibility in space use in architectural design evolves strategies that allow innovations such as multiple use of spaces. The study concludes that these strategies improve affordability as less financial resources spread over time are needed in achieving habitable unit when compared to designs that are rigid and conventional in nature. In a similar study on the impact of flexibility principle on the efficiency of interior spaces, Adulpader, Sobah and Abdullah (2014) discovered that it aids in offering architectural solutions that maximize the functional use of small spaces. Esenwein (2016) supports the notion of flexibility in space use in architectural design, which when linked to core housing affordability, has cost reduction advantage of simplicity in flexible plans. By this, a room could handle multiple functions (flexibility in space use). The case of the sitting 
room and kitchen serving the multi-purpose use also for dining and food storage correspondingly is an example. Tran (2006) deduces from field work that the provision of optimum flexible spaces contributes to the economic (cost) performance of housing, because the larger the floor area the costlier the house obviously. Flexible spaces authenticate the functionality of the core housing unit in performance of dual or multi-purpose activities. Napier (2002) also, in the study of the origin and spread of core housing, found that the flexibility in sub-division of internal spaces by future addition of internal walls after occupation helped in improving the affordability of core housing. This is because the elimination of the cost of constructing the internal walls of the initial core house, made possible in the open plan idea (Esenwein, 2016) and strengthened by the principle of flexibility in space use in architectural design, reduces its price. Other studies: Waibel, Eckert and Bose (2007); Gattoni, Goethert and Chavez (2011); Indrawan, Faqih and Purnomo (2012); and Larissa (2013) equally uphold the importance of flexibility in space use in architectural design in achieving affordability in low-cost housing.

Correspondingly, flexibility in space use in architectural design in relation to core housing affordability can be summed up under the following variables, namely:

(i) flexibility in use of sitting room also for dining;

(ii) flexibility in use of kitchen also for food storage; and

(iii) flexibility in sub-division of internal spaces after occupation.

From the above, it is seen that the principle of flexibility in space use in architectural design enables core house prototypes designed with flexible spaces to be put into optimum use because of their unstructured and elastic nature. Consequently minimal initial core units can be designed alongside this principle with the result of cutting down the price of the habitable unit when compared with the whole house (full-provision) alternative. Reduction in house price of initial unit invariably promotes housing affordability, as less financial resources would be needed to equip a household with a habitable unit. This measure equally would lead to the increase of the production scale of the core houses such that more beneficiaries are reached.

Studies abound on the subject of flexibility in space use in architectural design in relation to core housing affordability and this review has outlined the variables that make it up. However, there is dearth of knowledge on how far the architectural designs of core housing schemes developed have fared with regard to this attribute. This knowledge is necessary in order to equip design professionals with relevant information on what areas to look out for in planning for future core housing schemes; in order not to compromise the flexibility in space use principle. There is therefore need to examine the existing core housing schemes in order to know if flexibility in space use is reflected in their architectural designs.

\section{Theoretical framework}

This study is on examining flexibility in space use in the architectural designs of core housing schemes in Anambra State of Nigeria. Apart from establishing what constitutes flexibility in space use in architectural design in relationship to core housing affordability, the study was set out to know if this attribute is reflected in the architectural designs of the existing public core housing schemes in Anambra State. The study is relying on the theoretical foundation of 
the Functionalism Theory of Fitness to Purpose in Architecture. It is therefore necessary to explain what this theory stands for and to establish the link between it and the study focus.

According to Zurko (1957), there is no single definition upon which all functionalists agree, however, they all hold the basic premise in architecture that form should follow function. This becomes a guiding principle for the designer and a standard with which to measure architecture. Routio (2007), in line with this, notes that the intended uses of buildings have certainly influenced their architecture long before the emergence of first architects or theories. Zurko (1957) equally believes there is evidence from the history of architecture that at different times and places architects had either used the function of the building as a framework, or had unconsciously followed the idea of close relationship of form to function, in constructing a design. Routio (2007) traced functionalism in Architecture, which is a theory that architects should design buildings based on their purposes, back to the Vitruvian triad and continued to the works of Louis Sullivan, Ottor Wagnar and later Frank L. Wright who influenced the functionalism theory in architecture. In the Vitruvian triad 'utilitas' (utility, convenience, commodity) stands alongside 'venustas' (beauty) and 'firmitas' (firmness) as one of the three classic goals of architecture (Routio, 2007). Likewise, functionalism believes that the function of a building should be reflected in its design, and the materials used in construction; hence the term "form follows function".

The above views on functionalism are made clearer in Leon Battista Alberti's Functionalisn Theory of Fitness for Purpose. According to Zurko (1957), Alberti in the Thesis: The Architecture of Leon Battista Alberti, which was post-humously published in 1485 by James Leoni, had stressed that Architecture is largely an outgrowth of necessity and convenience, and that it is not primarily subservient to pleasure and recreation. The Fitness for Purpose theory, as stated by Aberti in his thesis propounds that the proper way to study architecture is to study the uses of buildings and the nature of men for whose use the buildings are intended (Zurko, 1957). Zurko (1957), equally reports the theoretical principles that Pugin put forth in the book "True Principles of Pointed or Christian Architecture" published in 1841. Pugin in the book stated that the greatest test of architectural beauty or excellence is the fitness of the design for the purpose intended.

In applying the Functionalism Theory of Fitness for Purpose in Architecture to the context of this study it is apt to first consider what the basic use of core housing is, this house type in this context taking for the building referred to in the theory. The basic use of core housing is the provision of simple minimal shelter for the household who otherwise may not access housing, such that this minimal shelter accommodates the basic functions that are usually performed in a house, namely: sitting, cooking, food storage, eating, sleeping and bathing. The notion of the minimal shelter catering for the basic functions is made possible by the provision of dual/multi-functional spaces enriched with flexibility in space use in place of the conventional structured and dedicated spaces for separate functions. Functionalism Theory of Fitness for Purpose in Architecture therefore explains the necessity of ensuring the achievement of the basic use of core housing in the provision of flexible spaces with the potential to achieve dual/multi-purpose usage since this attribute is what makes the basic compact space provided work. Next would be the need to look at the nature (characteristics) of the people for whose use core housing is intended, in order to know what their major challenge in housing provision is. Core housing strategy has been shown to be identified with people earning low incomes, who cannot afford whole houses (Abrams, 1964), and as such likely to be having housing challenges. They therefore need just an affordable shelter which 
can cater for their basic housing needs foremost to move into and then upgrade later. The provision of a compact flexible space (initial core house) in order to increase affordability is in line with the view of Zurko (1957) that architects should look into contemporary problems (affordability) with the perspective of inventing new forms (compact flexible spaces) to solve them. Functionalism Theory of Fitness for Purpose in Architecture can therefore be relied on as a theoretical basis for this study.

\section{METHODOLOGY}

The coverage of this study encompasses the existing public core housing estates proposed and built by the Federal and State governments in the public housing programme in Anambra State, Nigeria. However, it was confirmed from preliminary investigation that the core houses developed at Federal Low-Cost Housing Estate, Trans-Nkisi, Onitsha and AHOCOL Niger Close Housing Estate, G.R.A, Onitsha have been partially/totally demolished respectively.

All the public core housing estates that have survived and are still operating are located in Awka capital city. Awka capital city, the capital of Anambra State in Nigeria is therefore the study area for this research. According to United Nations Human Settlements Programme, UN-HABITAT, (2009). Anambra State is one of the 36 states of the Nigerian Federation (Figures 1 and 2) and one of the five states in the South-East Geo-political zone of the country, Nigeria.

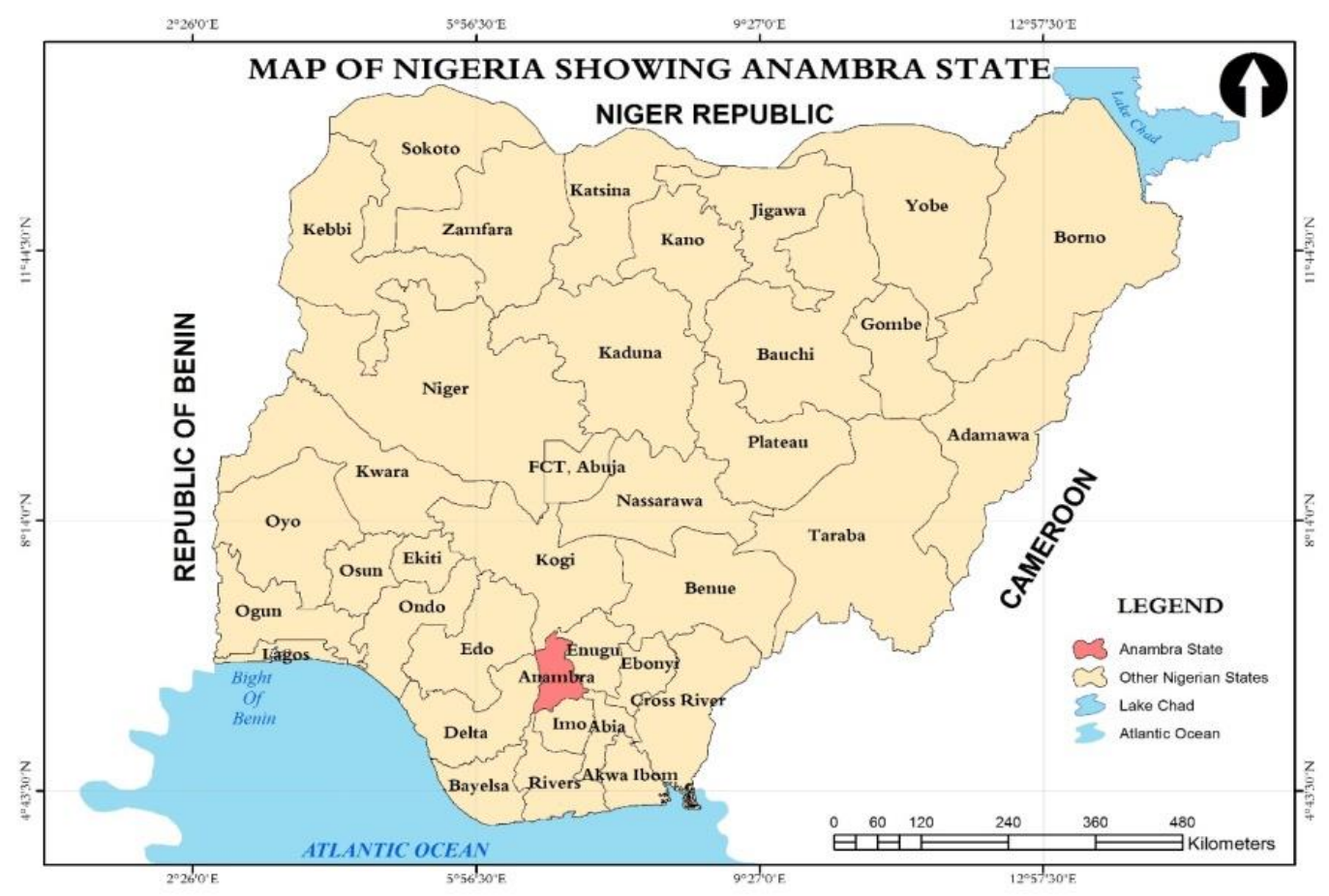

Figure 1: Map of Nigeria Showing Anambra State.

Source: Office of the Surveyor General of the Federation, Abuja 2012. 


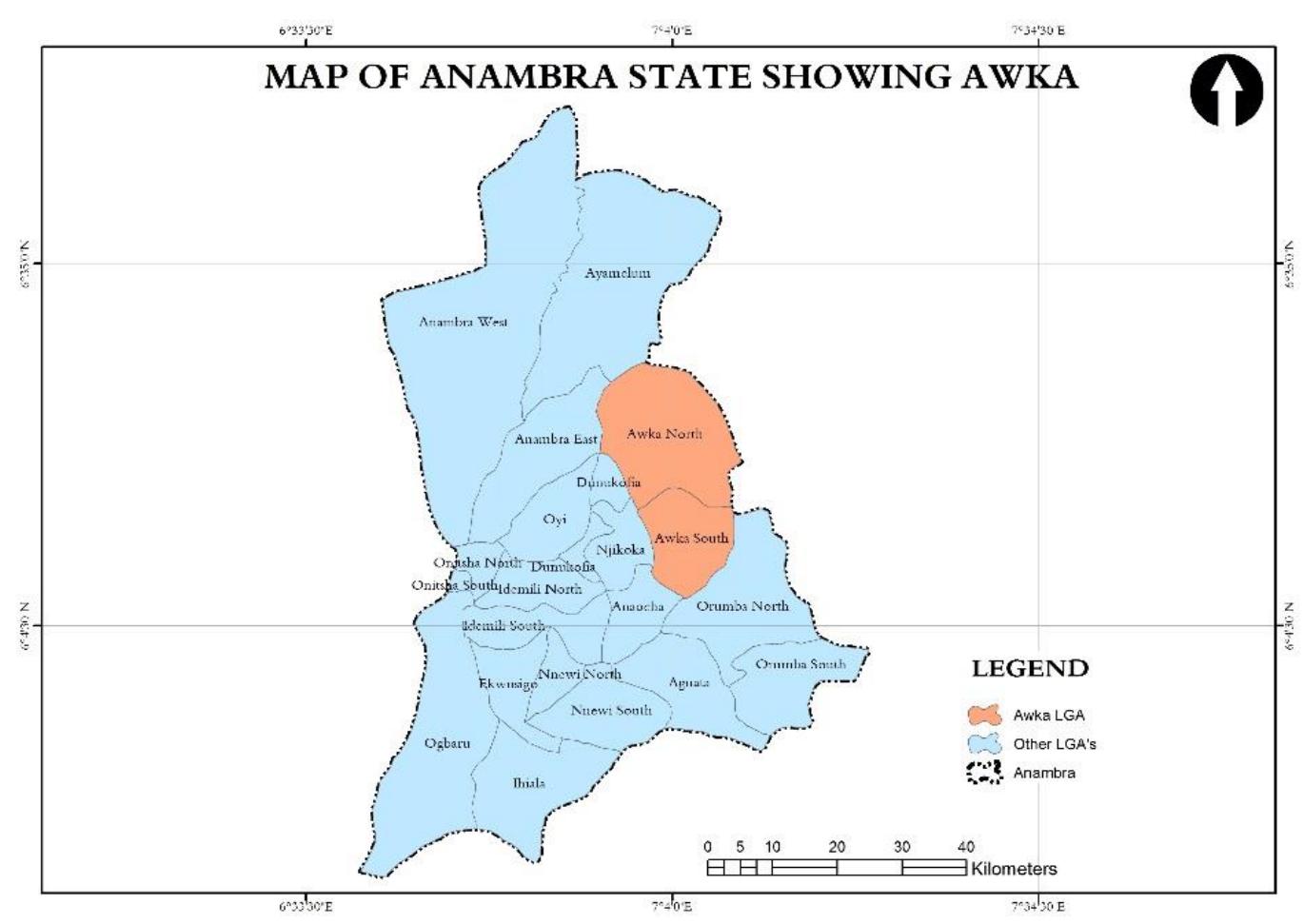

Figure 2: Map of Anambra State Showing Awka.

Source: Office of the Surveyor General of the Federation, Abuja 2012.

Awka capital city is found about 300 metres above sea level. It is fairly level having two ridges, which appear in a north - south direction. UN-HABITAT (2009) notes that the minor ridge rises at Ifite - Awka which is about 150 metres above sea level and that the plain surrounding this ridge hosts the area under consideration, Awka capital city. A thick sequence of shale and sand stones formed in the Paleocene age can be found underlying this area. A rich bed of clay and sands that contains seams of lignite cover it. UN-HABITAT (2009) identifies three notable soil types, namely: loamy, clay and fine white sands, and laterite. The laterite is loose and poorly compacted and is easily eroded. It is moderately permeable. This area under study can be found within the zone known as the rain forest zone of Nigeria. However, as a result of consistent agriculture and full economic activities on the land the vegetation is transforming to a mixed savannah type. Rain forest trees such as Iroko, Orange, and Mango, Palm, Cola nut and Coconut trees could be found in the residential areas and along stream courses. High temperatures are recorded in Awka capital city, having about $27-28^{0} \mathrm{C}$ normally and a peak of about $35^{\circ} \mathrm{C}$ during the hottest period between which spans between February and April (UN-HABITAT, 2009). Covering the middle of the rainy season to the harmattan period, the coolest period occurs from mid-July through December to early January. This warm temperature scenario encourages outdoor activities. High humidity and rainfall are prevalent in this area. According to UN-HABITAT (2009), the study area is located within the tropical wet climate zone with clearly known wet season and dry seasons; annual rainfall from 1979-1989 being recorded as $1,485.2 \mathrm{~mm}$ with a mean monthly figure of 
$50 \mathrm{~mm}$. About eight of the twelve months of the year constitute the rainy season while the remaining four are known to be dry. These yearly seasons are as a result of the activities of the two predominant winds in this area namely: the south-west monsoon wind and the northeast trade wind. The south-east monsoon wind comes from the Atlantic ocean, the north-east trade wind from the Sahara desert. Sometime between the months of November and February, the peculiar harmattan period takes place for about two weeks within the dry season. This period is very dry and dusty in the atmosphere.

National Population Commision of Nigeria, NPC, (2006) estimated the population of Awka capital city as 113,660. This comprised of Awka (86,593), Amawbia (21,773) and Okpuno $(5,294)$. Applying the annual growth rate of $3.2 \%$, according to NPC (2006), the population of 220, 094 is projected for the year 2020. As concerns the settlement pattern in the Awka capital city, two distinct segments are noticeable, namely: the built-up traditional setting as well as the sparsely developed/developing areas around it. The characteristics of the traditional setting can be summerized as being overcrowded, unplanned, and without a good road systems. Large open lands surround the few houses. These open lands are used for agricultural purposes. In order for proper planning to be attained, the settlement characteristics is crucial and should be brought into focus. In Awka town itself two major components are noticed. The first is the older indigenous Igbo settlement with a palace and a market square at the centre that provides sufficient open spaces for recreation, religious, socio-cultural and economic activities. A compact nature of individual family compounds walled and linked up with untarred roads and pathways are also noticeable. The second is the newly developing area merging into the old settlement but separated by the Enugu-Onitsha expressway.

In view of the types of data required for this study, Mixed method research design was adopted. The residents of all existing public core housing estates (federal government and state government owned) developed in the public housing programme of Anambra State formed the population of the study. A total number of 7 core housing estates, having 1,173 housing units (all bungalows), and 1,430 dwelling units, were developed in Anambra State (916 detached, and 257 semi-detached having 2 dwelling units occupied by different households). As has been earlier observed, the core houses developed at Federal Low-Cost Housing Estate, Trans-Nkisi, Onitsha and AHOCOL Niger Close Housing Estate, G.R.A, Onitsha have been partially/totally demolished respectively. The estates under study therefore are the remaining 5 estates developed by the Anambra State Home Ownership Company Limited (AHOCOL), Awka and the Anambra State Housing Development Corporation (ASHDC), Awka. These comprise of 953 housing units and 1,210 dwelling units (257 were of the semi-detached type with 2 dwelling units occupied by different households) (Okoye, Onyegiri \& Okafor, 2021). The intended residents for the core houses were determined by computing the maximum monthly income of households who cannot afford whole houses. The affordability yardstick of not more than 2.5 times household annual income (Grimmes, 1976 and Feins and Lane, 1981 cited in Ndubueze, 2009) was applied because Anambra housing policy is based on outright house purchase without mortgage financing (see Personal interview protocol of the head of Estate Management department of ASHDC during pilot survey - Appendix B). The price of the least of the whole houses developed in Anambra State as obtained from the personal interview protocol of the Head of Quantity Surveying department of ASHDC during the pilot survey (Table 1 and Appendix C) was also applied (Okoye, Onyegiri \& Okafor, 2021). A total of 6 Million Naira $(\$ 15,483.87)$ was obtained. 
Table 1: Average Land/Building Costs of 1-Bedroom, 2-Bedroom and 3-Bedroom FullProvision/Finished House Types within the City as at the Year 2016

\begin{tabular}{cllll}
\hline S/N & Prototype & Building Cost $(\mathbf{N})$ & $\begin{array}{l}\text { Land } \\
\operatorname{Cost}(\mathbf{N})\end{array}$ & $\begin{array}{l}\text { Selling } \\
\text { Price }(\mathbf{N})\end{array}$ \\
\hline 1. & 1-bedroom & $2 \mathrm{M}\left(300 \mathrm{~m}^{2}\right)$ & 4 million & 6 million \\
2. & 2-bedroom & $3 \mathrm{M}\left(360 \mathrm{~m}^{2}\right)$ & 4.8 million & 7.8 million \\
3. & 3-bedroom & $4.1 \mathrm{M}\left(450 \mathrm{~m}^{2}\right)$ & 6.3 million & 10.4 million
\end{tabular}

Source: Field work (2016), Compiled from Infomation obtained from the Head of the Quantity Surveying Department, Anambra State Housing Development Corporation, Awka

By imputing 6 Million Naira $(\$ 15,483.87)$ and 2.5 x Household Annual Income as derived from the literature review 2.2 - (Okoye, Onyegiri \& Okafor, 2021), the figure N200, 000 (\$516.13) was realized as the maximum monthly income of households who cannot afford whole houses and therefore the intended residents for the core houses. Furthermore, in line with the fact that this study is only interested in the residents who fall into the group of those intended for the core housing scheme and not all the categories of residents, the residents whose average monthly incomes do not exceed N200, $000(\$ 516.13)$ were isolated to form this group. On the whole, 540 households were isolated and noted from the 1,210 dwelling units as belonging to the group of intended residents for the core houses during the pilot survey. Taro Yamane's formula was used to arrive at the sample size of 230. The sample size of 230 was distributed according to the contribution each estate/prototype is making to the total population of 540 dwelling units, through proportionate stratified random sampling procedure (Table 2)

Table 2: List of Existing Public Core Housing Estates in Anambra State for Study According to Prototypes/Dwelling Units

\begin{tabular}{|c|c|c|c|c|c|}
\hline $\mathbf{S} / \mathbf{N}$ & Name of Estate & $\begin{array}{c}\text { 1- } \\
\text { bedroom }\end{array}$ & $\begin{array}{c}2- \\
\text { bedroom }\end{array}$ & $\begin{array}{c}\text { 3- } \\
\text { bedroom }\end{array}$ & $\begin{array}{c}\text { Total } \\
\text { Dwelling } \\
\text { Units }\end{array}$ \\
\hline 1. & $\begin{array}{l}\text { AHOCOL Think Home Estate Phase } \\
\text { 1, Agu-Awka, Awka (PROTOTYPE } \\
\text { AHOCOL 1) }\end{array}$ & & & 19 & 19 \\
\hline 2. & $\begin{array}{l}\text { AHOCOL Think Home Estate Phase } \\
\text { 2, Agu-Awka, Awka (PROTOTYPE } \\
\text { AHOCOL 2) }\end{array}$ & & & 42 & 42 \\
\hline 3. & $\begin{array}{l}\text { AHOCOL Oganiru Housing Estate, } \\
\text { Agu-Awka, Awka (PROTOTYPE } \\
\text { AHOCOL 3) }\end{array}$ & & & 26 & 26 \\
\hline 4. & $\begin{array}{l}\text { AHOCOL Inner City Layout, } \\
\text { Nkwelle, Awka (PROTOTYPE } \\
\text { AHOCOL 4) }\end{array}$ & & 3 & & 3 \\
\hline
\end{tabular}


African Journal of Economics and Sustainable Development

ISSN: 2689-5080

Volume 4, Issue 2, 2021 (pp. 39-85)

www.abjournals.org

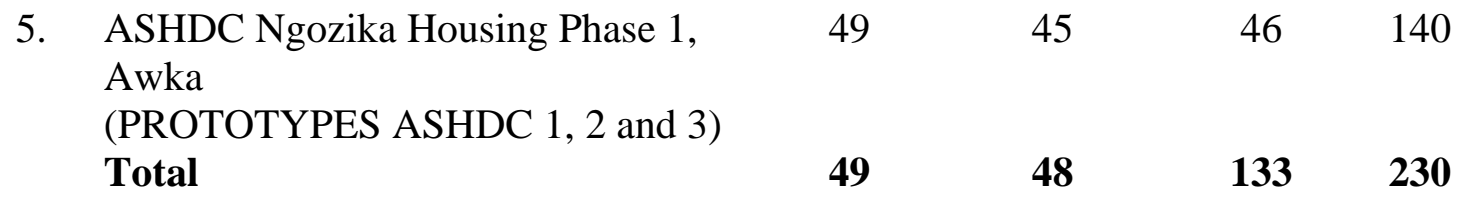

Source: Fieldwork (2016)

The following (Table 3) constitute the existing public core house prototypes in Anambra State: (i) semi-detached 3-bedroom bungalow at AHOCOL Phase (AHOCOL 1) - 19 dwelling units; (ii) semi-detached 3-bedroom bungalow at AHOCOL Phase 2 (AHOCOL 2) 14 dwelling units; (iii) detached 3-bedroom bungalow at AHOCOL Oganiru Housing Estate, Agu-Awka (AHOCOL 3) - 26 dwelling units; (iv) detached 2-bedroom bungalow at AHOCOL Inner City Layout, Nkwelle, Awka (AHOCOL 4) - 3 dwelling units; (v) detached 1-bedroom bungalow at ASHDC Ngozika Housing Estate, Phase 1, Ikwodiaku, Awka, (NGOZIKA 1) - 49 dwelling units; (vi) detached 2-bedroom bungalow at ASHDC Ngozika Housing Estate, Phase 1, Ikwodiaku, Awka, (NGOZIKA 2) - 45 dwelling units; and (vii) detached 3-bedroom bungalow at ASHDC Ngozika Housing Estate, Phase 1, Ikwodiaku, Awka, (NGOZIKA 3) - 46 dwelling units.

Table 3: List of Existing Public Core House Prototypes in Anambra State Showing Number of Dwelling Units

\begin{tabular}{|c|c|c|}
\hline $\mathbf{S} / \mathbf{N}$ & CORE HOUSE PROTOTYPE & $\begin{array}{c}\text { NUMBER OF } \\
\text { DWELLING UNITS }\end{array}$ \\
\hline 1. & $\begin{array}{l}\text { Semi-detached 3-bedroom bungalow at } \\
\text { AHOCOL Phase } 1\end{array}$ & 19 \\
\hline 2. & $\begin{array}{l}\text { Semi-detached 3-bedroom bungalow at } \\
\text { AHOCOL Phase } 2\end{array}$ & 42 \\
\hline 3. & $\begin{array}{l}\text { Detached 3-bedroom bungalow at } \\
\text { AHOCOL Oganiru Housing Estate, Agu- } \\
\text { Awka (AHOCOL 3) }\end{array}$ & 26 \\
\hline 4. & $\begin{array}{l}\text { Detached 2-bedroom bungalow at } \\
\text { AHOCOL Inner City Layout, Nkwelle, } \\
\text { Awka (AHOCOL 4) }\end{array}$ & 3 \\
\hline 5. & $\begin{array}{l}\text { Detached 1-bedroom bungalow at ASHDC } \\
\text { Ngozika Housing Estate, Phase 1, } \\
\text { Ikwodiaku, Awka, (NGOZIKA 1) }\end{array}$ & 49 \\
\hline & $\begin{array}{l}\text { Detached 2-bedroom bungalow at ASHDC } \\
\text { Ngozika Housing Estate, Phase 1, } \\
\text { Ikwodiaku, Awka, (NGOZIKA 2) }\end{array}$ & 45 \\
\hline 7.. & $\begin{array}{l}\text { Detached 3-bedroom bungalow at ASHDC } \\
\text { Ngozika Housing Estate, Phase 1, } \\
\text { Ikwodiaku, Awka, (NGOZIKA 3) }\end{array}$ & 46 \\
\hline
\end{tabular}

Source: Fieldwork (2016) 
From literature review, the following variables were identified as constituting flexibility in space use in architectural design of core housing schemes, namely: (i) flexibility in use of sitting room also for dining; (ii) flexibility in use of kitchen also for food storage; (iii) flexibility in sub-division of internal spaces after occupation.

Data for the study were sourced from: (i) relevant literary works; (ii) architectural drawings of the existing public core house prototypes in Anambra State (reproduced from Archival Records of Anambra State Housing Development Corporation, Awka) which consists of floor plans and elevations; (iii) photographic images of the prototypes; and (iv) personal interview protocols. Data collection was carried out between the months of February 2016 and October 2017.

Data presentation was through the use of figures depicting architectural drawings and, plates showing photographic images. Data on ascertaining the reflection of the qualitative attribute "flexibility in space use in architectural design" of the existing public core housing schemes in Anambra State were analysed by applying a rating of "Yes and "No" values to measure its inclusion or deficiency respectively, in terms of the variables: (i) flexibility in use of sitting room also for dining; (ii) flexibility in use of kitchen also for food storage; and (iii) flexibility in sub-division of internal spaces after occupation (see Observation Schedule, Appendix A). Mutiya (2015), in the study of housing affordability in Kenya, had used a similar rating of 1, 2 and 3 values for superior design, moderate design and inferior design respectively, to measure the qualitative variable "house design" in terms size of house and building material/finishes specifications. Likewise, the variables that determine flexibility in space use in architectural design were assigned ratings of "Yes and "No" values.

\section{RESULTS/FINDINGS}

\section{Results}

Objective 1: to review literature explaining what constitutes flexibility in space use in architectural design in relation to core housing affordability.

As was presented in the literature review section in 2.3 , flexibility in space use in architectural design in relation to core housing affordability incorporates (i) flexibility in use of sitting room also for dining; (ii) flexibility in use of kitchen also for food storage; and (iii) flexibility in sub-division of internal spaces after occupation. In relation to core housing affordability the attribute is shown to be crucial in fostering affordability of core housing schemes.

\section{Objective 2: to ascertain if flexibility in space use is reflected in the architectural designs of the existing public core housing schemes in Anambra State}

The result of ascertaining if flexibility in space use is reflected in the architectural designs of the existing public core housing schemes in Anambra State is presented according to the various prototypes and then summarized. Prototype 1 (Semi-Detached 3- bedroom bungalow at AHOCOL phase 1) and Prototype 2 (Semi-Detached 3- bedroom bungalow at AHOCOL phase 1) are presented together since they have the same typical site floor plans and 
elevations of the initial cores and the expansions. It is their photographic images that were shown differently. In the result summary also the two prototypes were separated.

Prototype 1 and Prototype 2: Semi-Detached 3- bedroom bungalow (core house) at AHOCOL phase 1 and AHOCOL phase 2 (AHOCOL 1 and AHOCOL 2)

(a)

$$
\text { Architectural drawings }
$$

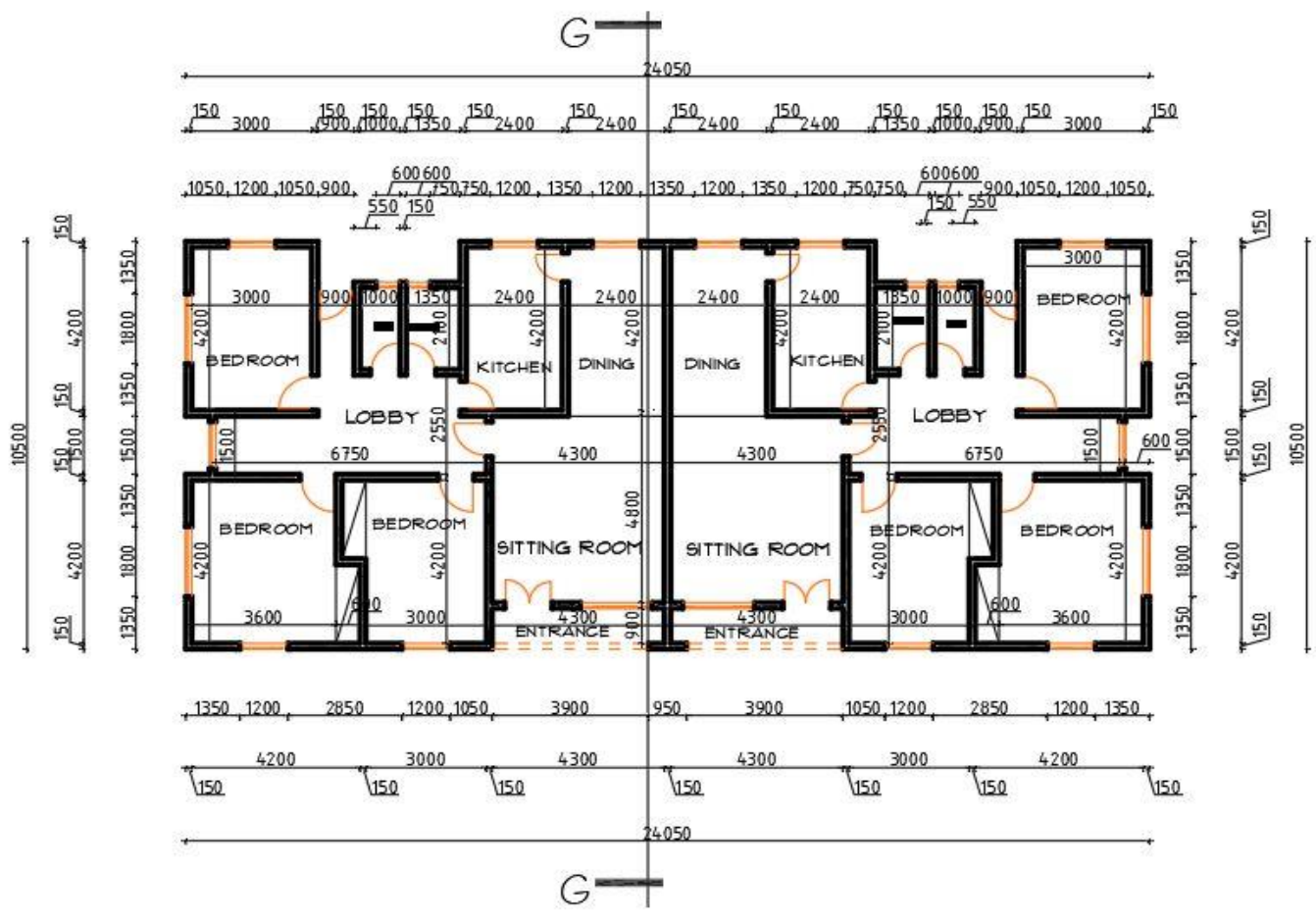

CORE HOUSE FLOOR PLAN

Figure 3: Floor plan of Initial Core, the Semi-detached 3 - Bedroom Bungalow at AHOCOL Phase 1 and AHOCOL Phase 2 (AHOCOL 1 and AHOCOL 2)

Source: Field Work (2017). Reproduced from Archival Records of Anambra State Housing Development Corporation, Awka.

Figure 3 is the floor plan of the semi-detached 3-bedroom bungalow (core house) developed at AHOCOL 1 and AHOCOL 2. 


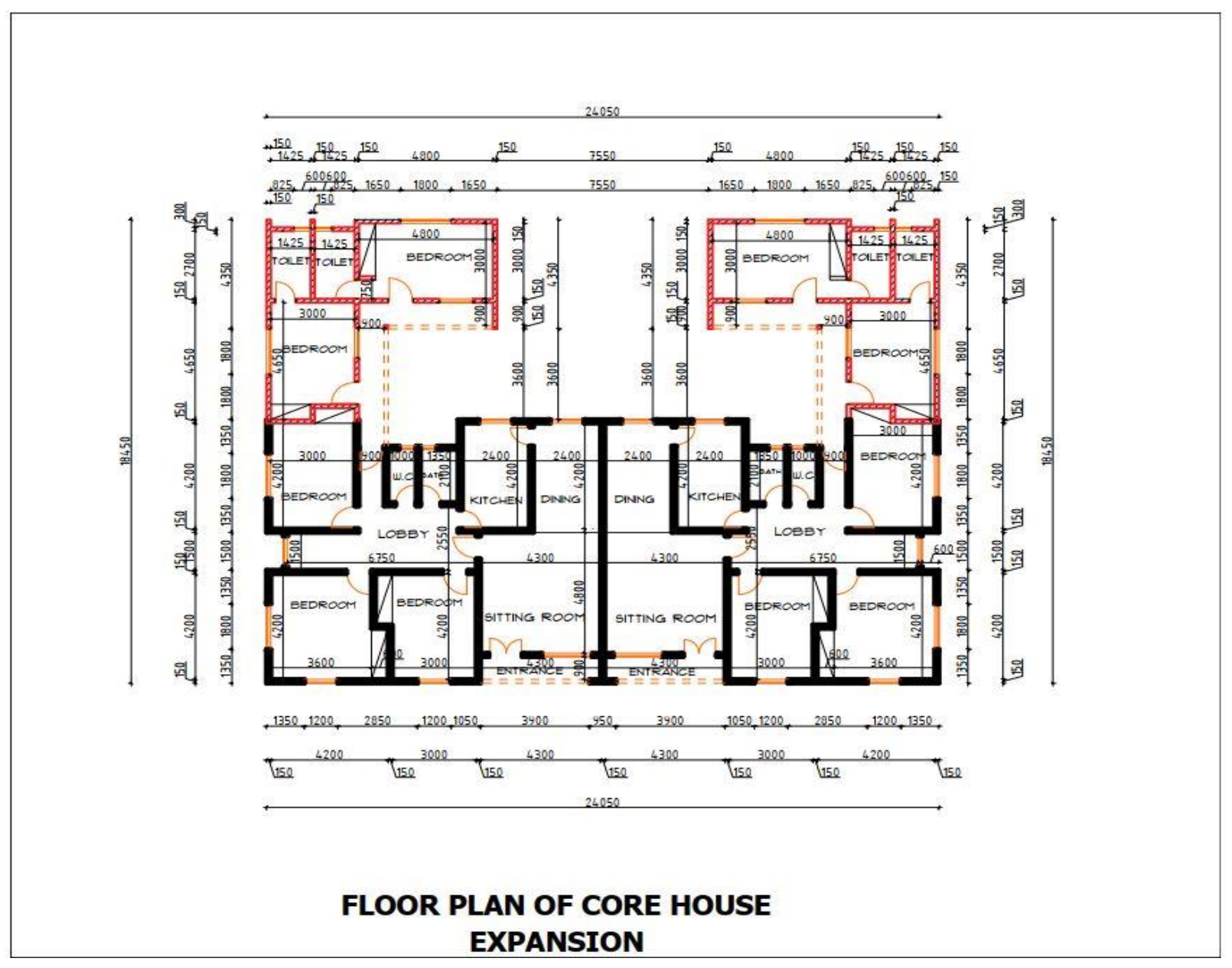

Figure 4: Floor plan for Core House Expansion, the Semi-detached 3- Bedroom Bungalow at AHOCOL Phase 1 and AHOCOL Phase 2 (AHOCOL 1 and AHOCOL 2)

Source: Field Work (2017). Reproduced from Archival Records of Anambra State Housing Development Corporation, Awka.

Figure 4 is the floor plan for core house expansion of the semi-detached 3 - bedroom bungalow (core house) developed at AHOCOL 1 and AHOCOL 2. 


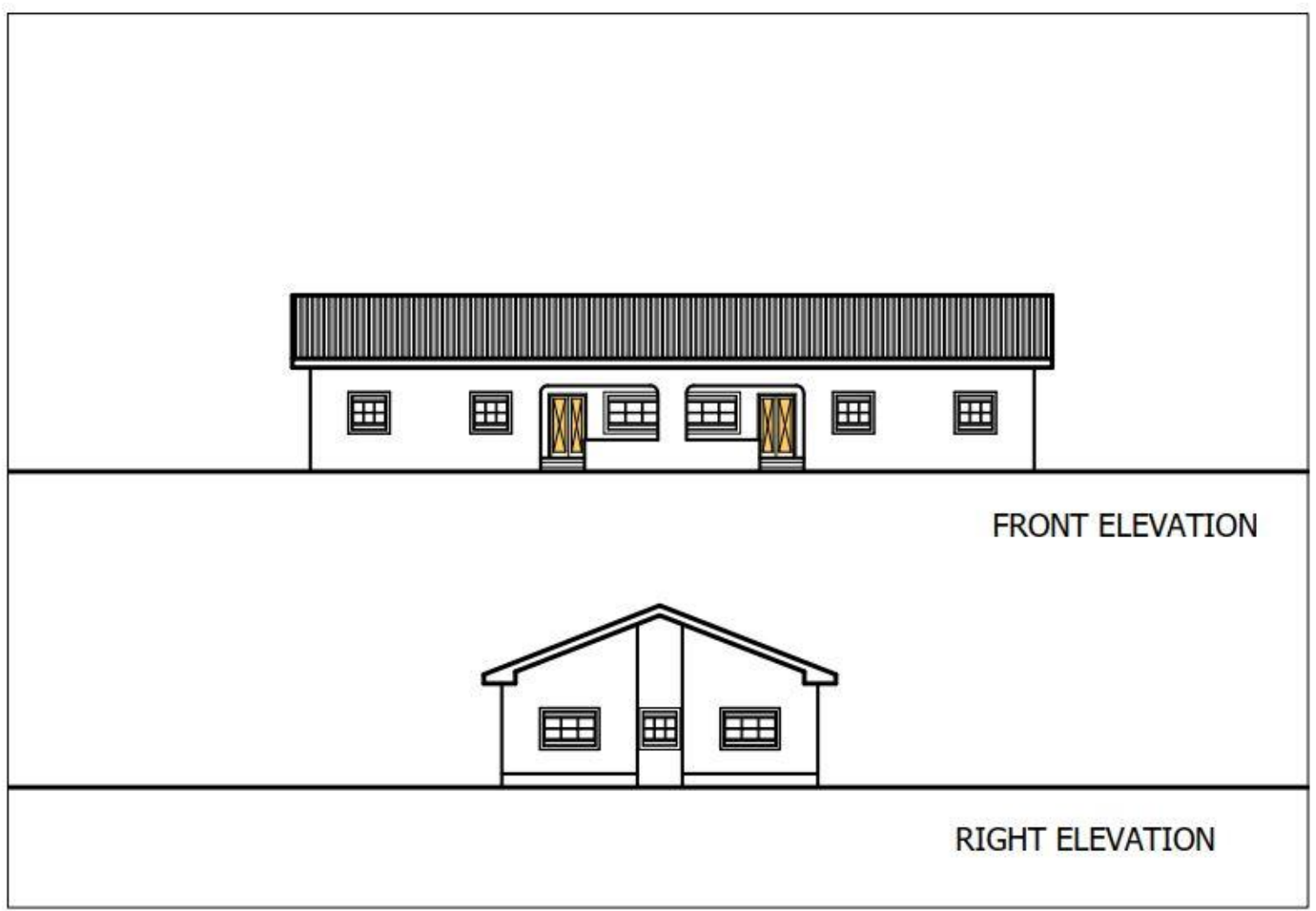

Figure 5: Front and Right Side Elevation, the Semi-detached 3- Bedroom Bungalow at AHOCOL Phase 1 and AHOCOL Phase 2 (AHOCOL 1 and AHOCOL 2)

Source: Field Work (2017). Reproduced from Archival Records of Anambra State Housing Development Corporation, Awka.

Figure 5 is the fornt and right side elevation of the semi-detached 3 - bedroom bungalow (core house) developed at AHOCOL 1 and AHOCOL 2. 
(b) Photographic images

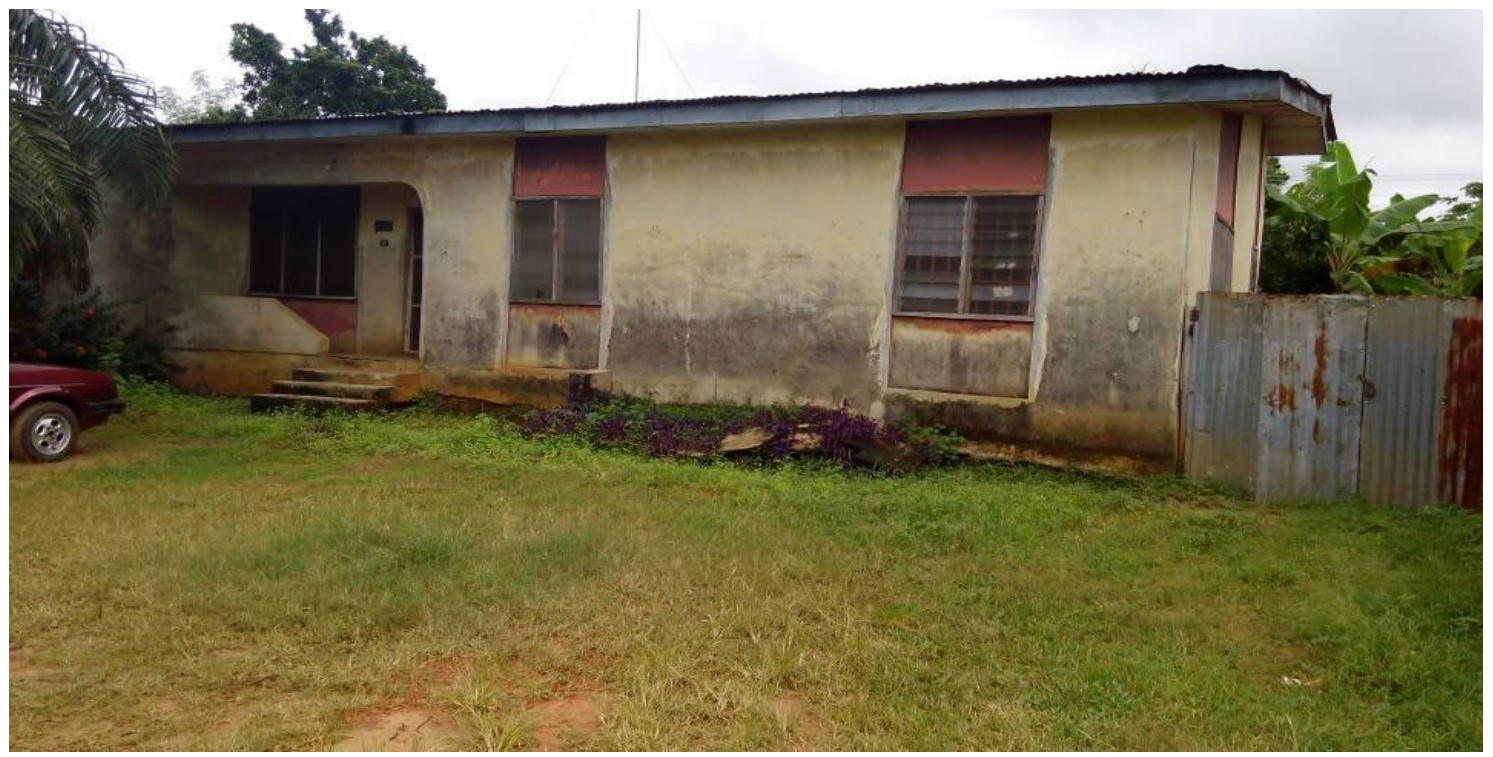

Plate 3: Photographic Image of the Semi-detached 3- Bedroom Bungalow at AHOCOL Phase 1 (AHOCOL 1) showing its appearance as a full-provision house rather than a partial-provision type (core house).

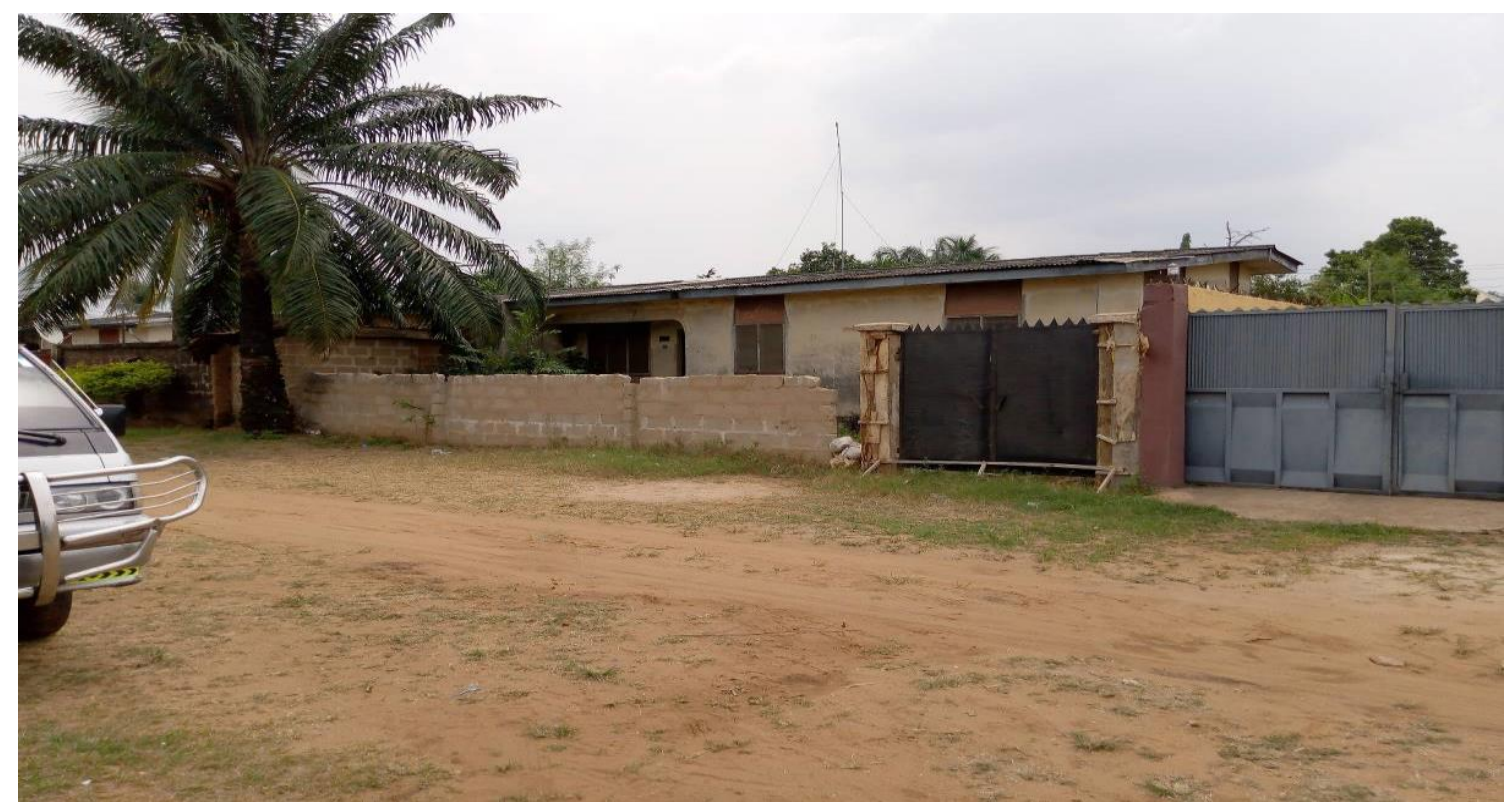

Plate 4: Photographic Image of the Semi-detached 3-Bedroom Bungalow at AHOCOL Phase 2 (AHOCOL 2) showing its appearance as a full-provision house rather than a partial-provision type (core house). 
(c) Result on asertaining the characteristic "flexibility in space use in architectural design" in the Semi-detached 3- Bedroom Bungalow at AHOCOL Phase 1 and AHOCOL Phase 2 (AHOCOL 1 and AHOCOL 2)

\section{(i) Variable 1 - Flexibility in use of sitting room also for dining.}

The sitting room was not designed for elastic use for sitting as well as eating as is done to portray flexibility in space use. This is because from Figures 3 and 4, it can be seen that a semi-structured and dedicated dining space distinct from the sitting room was provided. The prototype is rated No for this variable.

\section{(ii) Variable 2 - Flexibility in use of kitchen also for food storage}

The kitchen was designed for elastic use for cooking as well as food storage as is done to portray flexibility in space use, As can be seen in Figures 3 and 4 no separate food storage space was provided. The prototype is rated Yes for this variable.

\section{(iv) Variable 3 - Flexibility in sub-division of internal spaces after occupation}

All of the internal spaces (sitting room, dining, kitchen, bedrooms, toilet and bathroom) were sub-divided with permanent walls prior to occupation, as is shown in Figures 3 and 4. The floor plan did not indicate that some of the spaces were to be sub-divided after occupation, at owners' finanancial convenience, a consideration which would have portrayed flexibility in space use. The prototype is rated No for this variable. 
African Journal of Economics and Sustainable Development

ISSN: 2689-5080

Volume 4, Issue 2, 2021 (pp. 39-85)

www.abjournals.org

Prototype 2: Detached 3- bedroom bungalow at AHOCOL Oganiru Housing Estate, Agu-A wka (AHOCOL 3)

(a) Architectural drawings

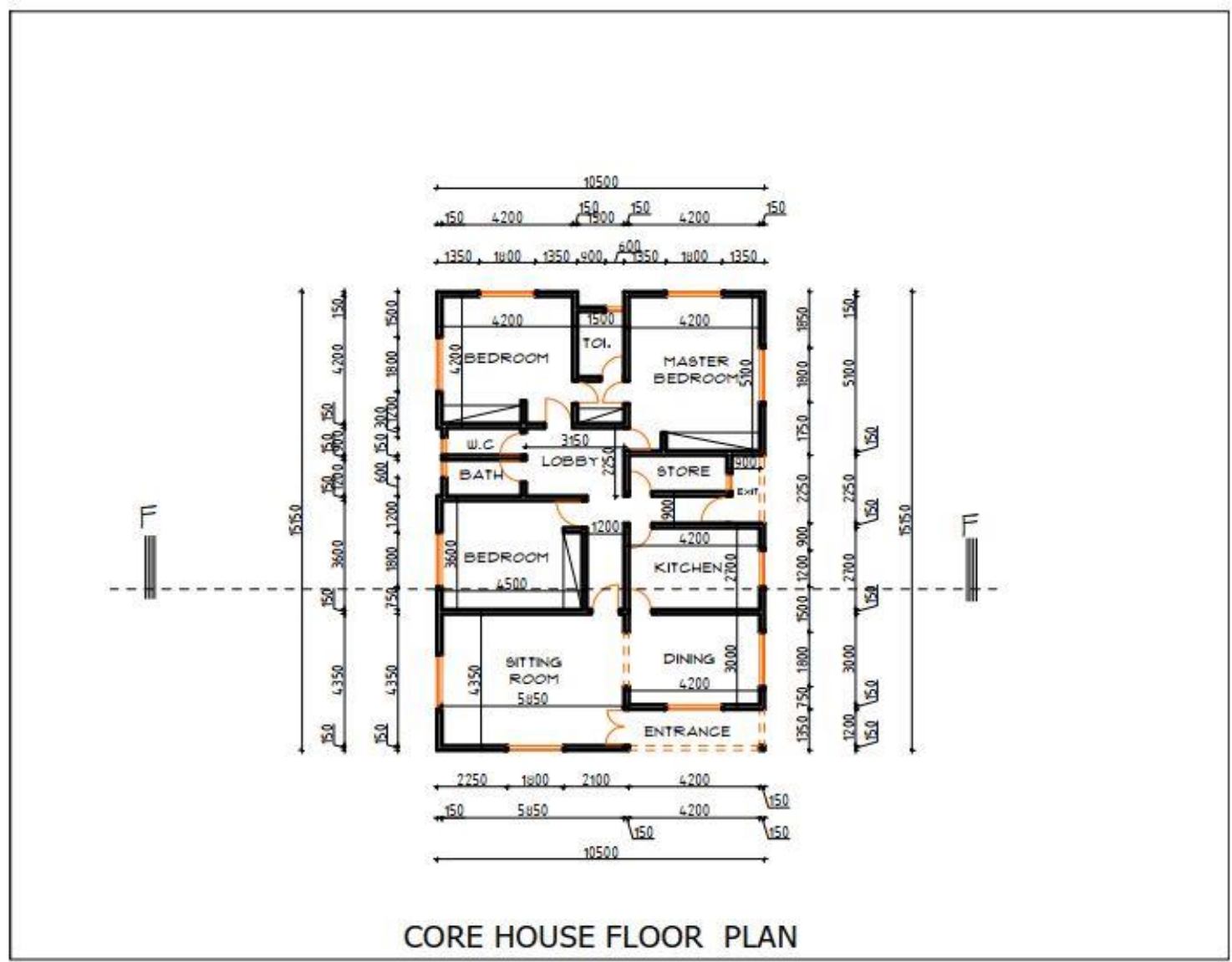

Figure 6: Floor plan of the Detached 3 -bedroom bungalow at AHOCOL Oganiru Housing Estate, Agu-Awka (AHOCOL 3)

Source: Field Work (2017). Reproduced from Archival Records of Anambra State Housing Development Corporation, Awka.

Figure 6 is the floor plan of the semi-detached 3-bedroom bungalow (core house) developed at AHOCOL Oganiru Housing Estate, Agu-Awka (AHOCOL 3). 


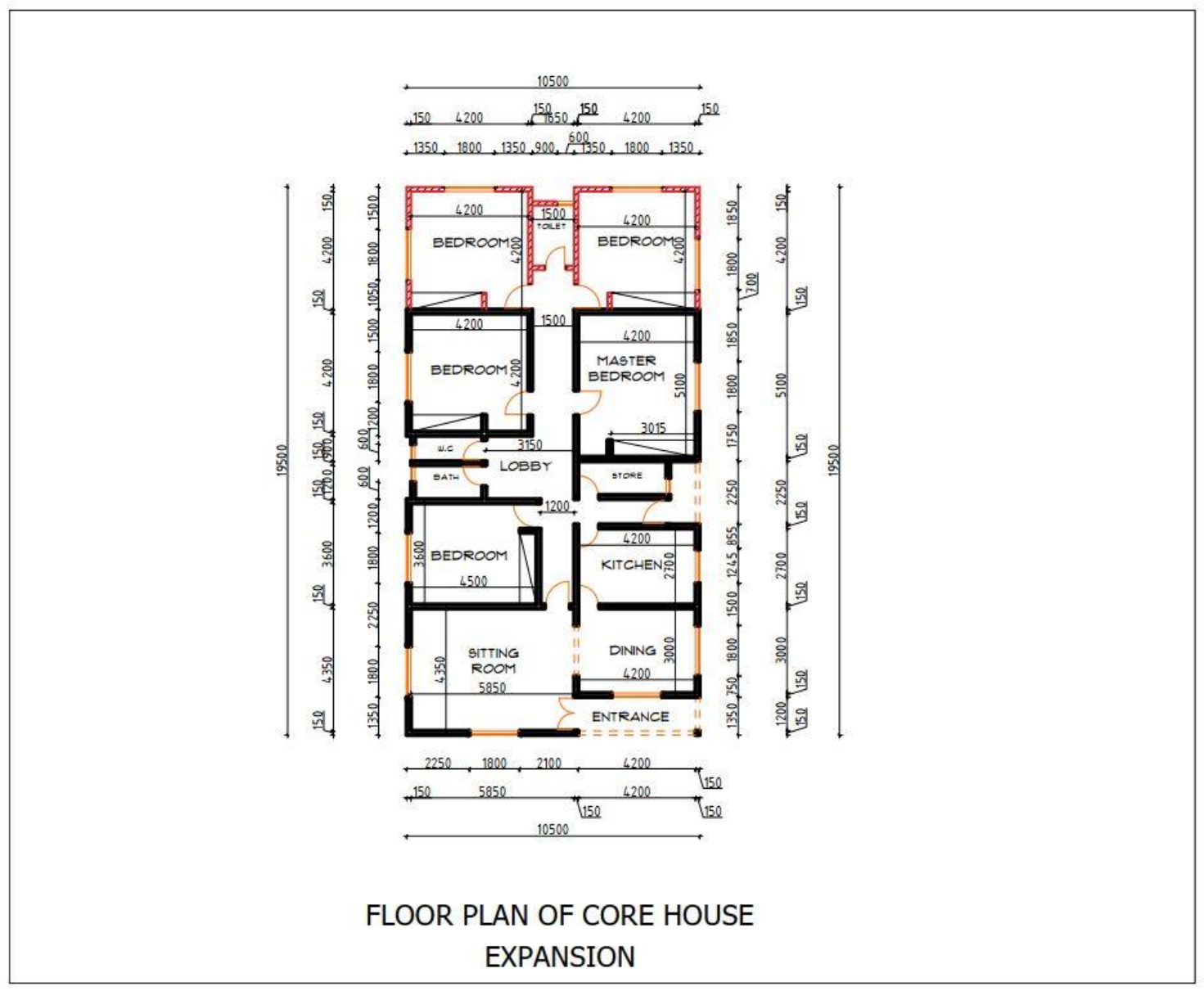

Figure 7: $\quad$ Floor Plan for Core House Expansion, the Detached 3 - bedroom Bungalow at AHOCOL Oganiru Housing Estate, Agu-Awka (AHOCOL 3)

Source: Field Work (2017). Reproduced from Archival Records of Anambra State Housing Development Corporation, Awka.

Figure 7 is the floor plan for core house expansion of the semi-detached 3 - bedroom bungalow (core house) developed at AHOCOL Oganiru Housing Estate, Agu-Awka (AHOCOL 3). 


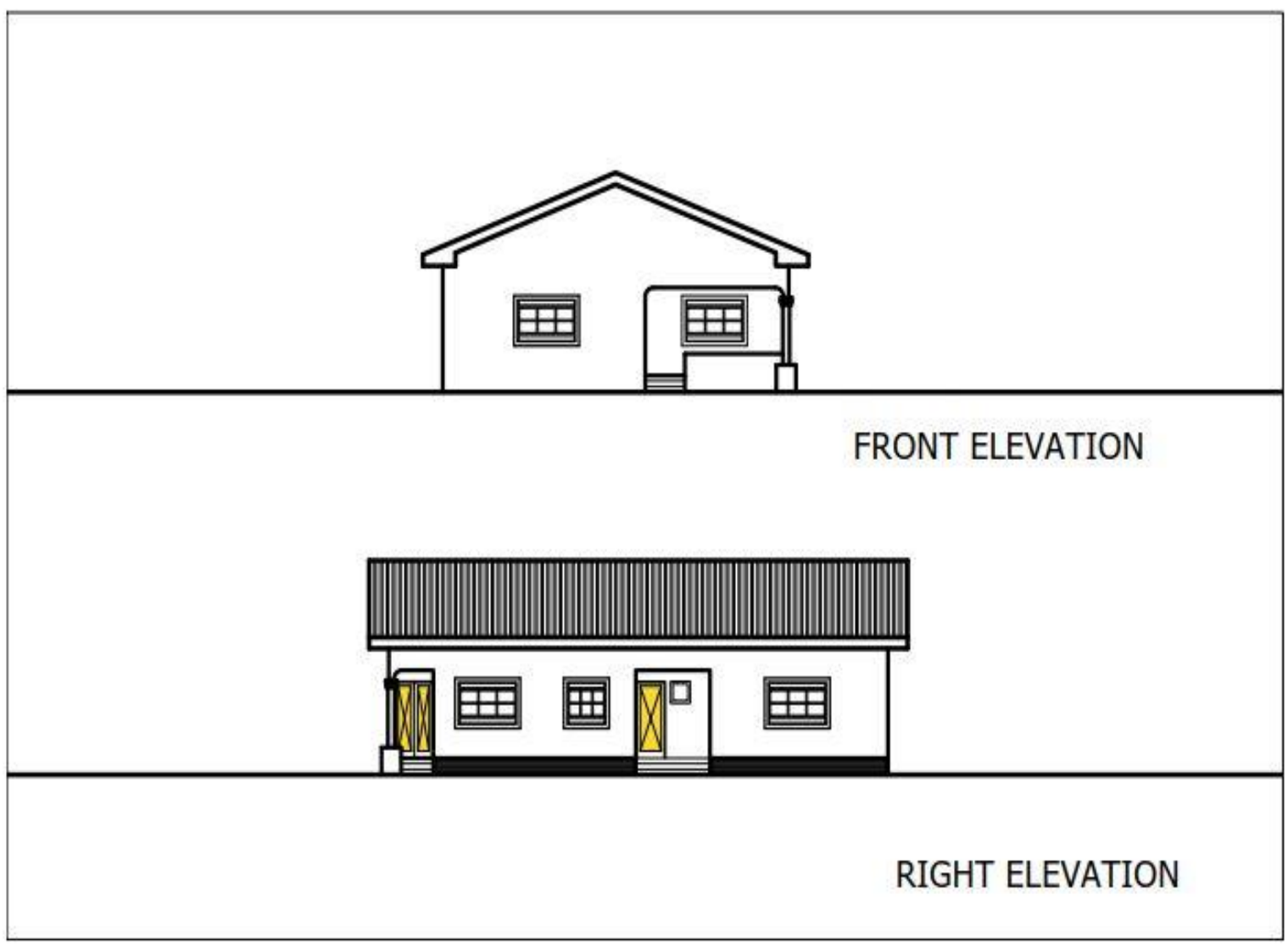

Figure 8: Front and Right Side Elevations of the Detached 3 -bedroom Bungalow at AHOCOL Oganiru Housing Estate, Agu-Awka (AHOCOL 3).

Source: Field Work (2017). Reproduced from Archival Records of Anambra State Housing Development Corporation, Awka.

Figure 8 is the front sand right side elevations of the semi-detached 3 - bedroom bungalow (core house) developed at AHOCOL Oganiru Housing Estate, Agu-Awka (AHOCOL 3). 
(b) Photographic image.

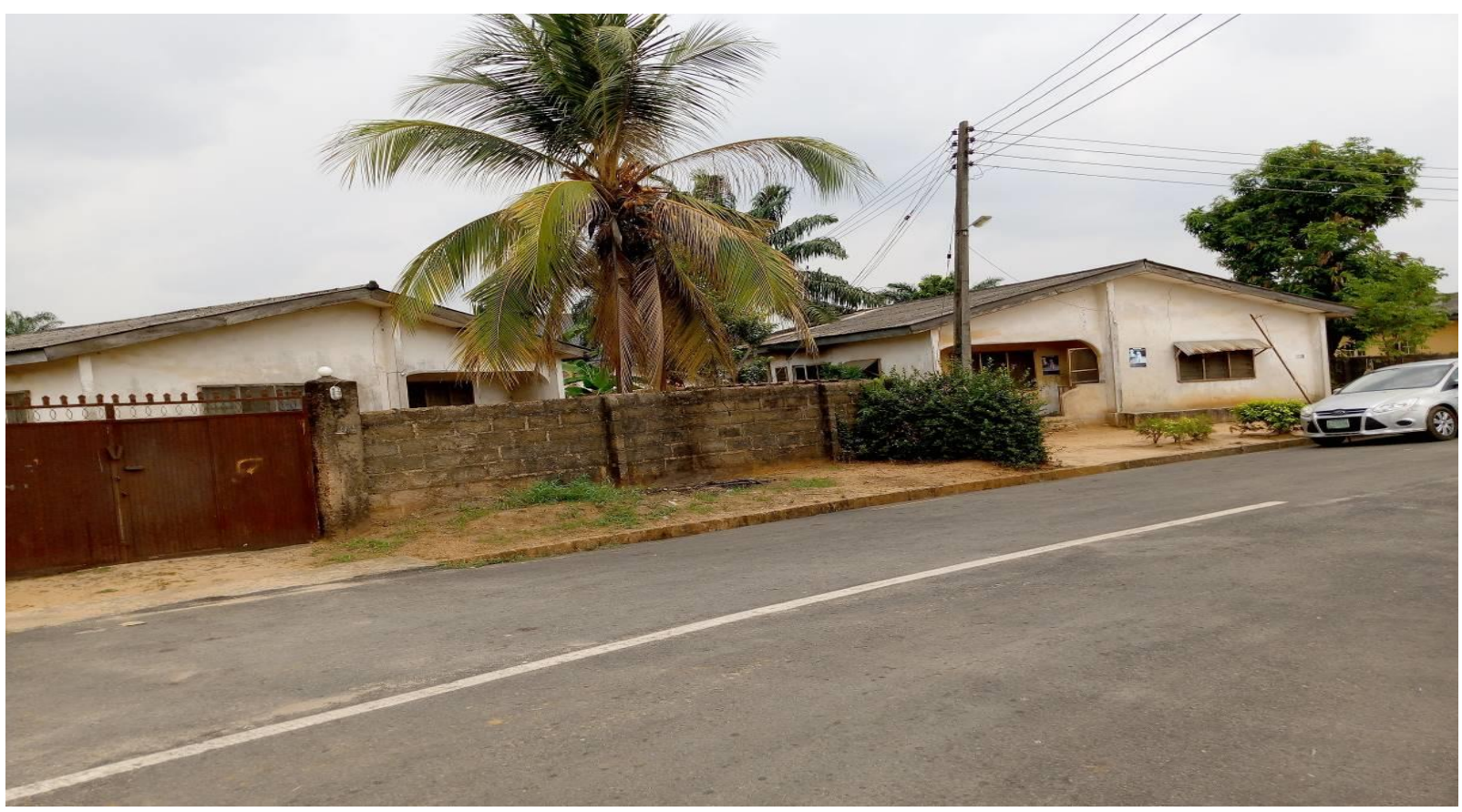

Plate 5: The Detached 3 - bedroom bungalow at AHOCOL Oganiru Housing Estate, Agu-Awka (AHOCOL 3) showing its appearance as a full-provision house rather than a partial-provision type (core house).

(c) Result on asertaining the characteristic "flexibility in space use in architectural design" in the detached 3- bedroom bungalow at AHOCOL Oganiru Housing Estate, Agu-Awka (AHOCOL 3)

(i) Variable 1 - Flexibility in use of sitting room for dining also.

The sitting room was not designed for elastic use for sitting as well as eating as is done to portray flexibility in space use. This is because from Figures 6 and 7, it can be seen that a semi-structured and dedicated dining space distinct from the sitting room was provided. The prototype is rated No for this variable.

\section{(ii) Variable 2 - Flexibility in use of kitchen for food storage also}

The kitchen was not designed for elastic use for cooking as well as food storage as is done to portray flexibility in space use, A separate food storage space was provided. This can be seen in Figures 6 and 7. The prototype is rated No for this variable.

\section{(iii) Variable 3 - Flexibility in sub-division of internal spaces after occupation}

All of the internal spaces (sitting room, dining, kitchen, bedrooms, toilet and bathroom) were sub-divided with permanent walls prior to occupation, as is shown in Figures 6 and 7. The floor plan did not indicate that some of the spaces were to be sub-divided after occupation at 
owners' finanancial convenience, which portrays flexibility in space use. The prototype is rated No for this variable.

\section{Prototype 3: Detached 2- Bedroom bungalow at AHOCOL Inner City Layout, Nkwelle, Awka (AHOCOL 4)}

\section{(a) Architectural drawings}

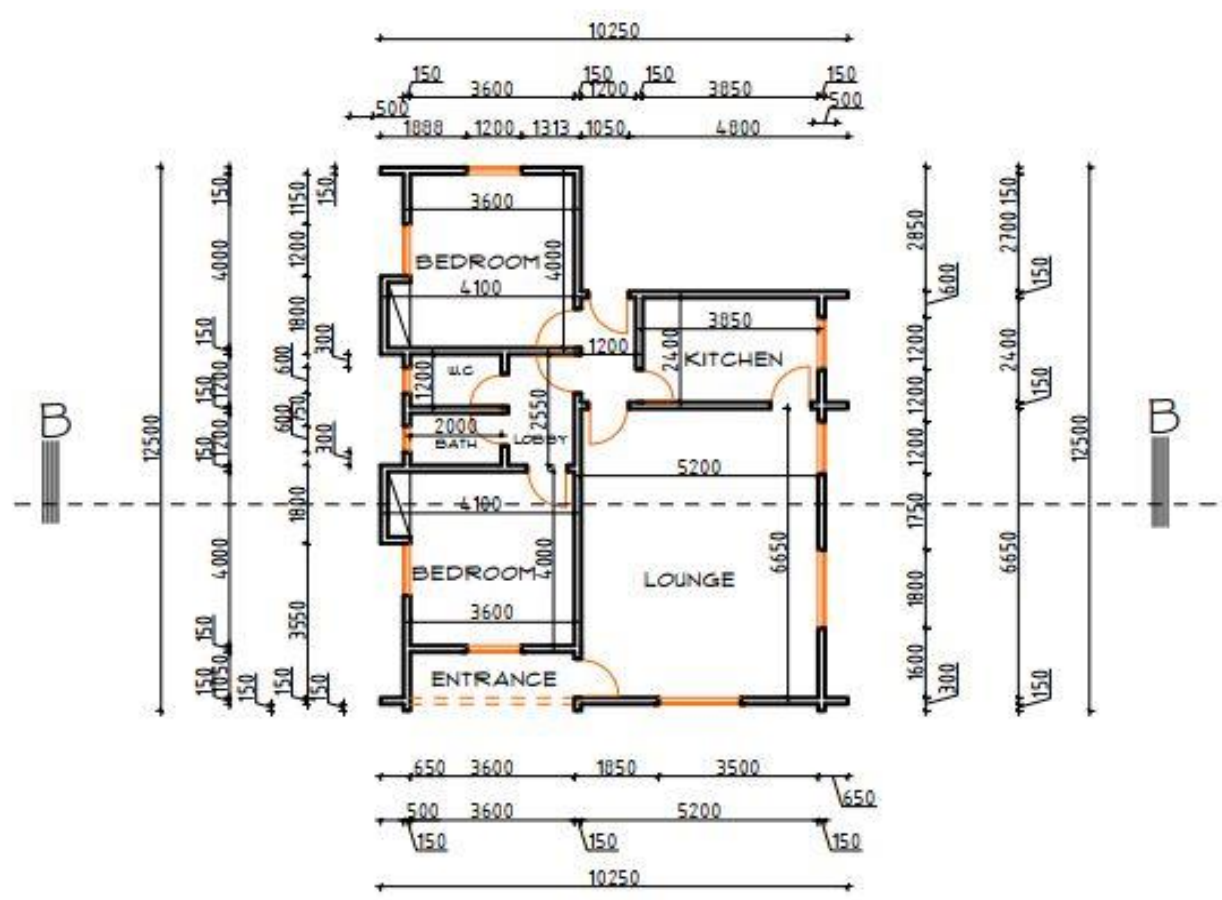

CORE HOUSE FLOOR PLAN

Figure 9: Floor Plan of the Detached 2- bedroom bungalow (Core House) at AHOCOL Inner City Layout, Nkwelle, Awka (AHOCOL 4)

Source: Field Work (2017). Reproduced from Archival Records of Anambra State Housing Development Corporation, Awka.

Figure 9 is the site plan of the Detached 2-bedroom bungalow (core house) at AHOCOL Inner City Layout, Nkwelle, Awaka (AHOCOL 4). 


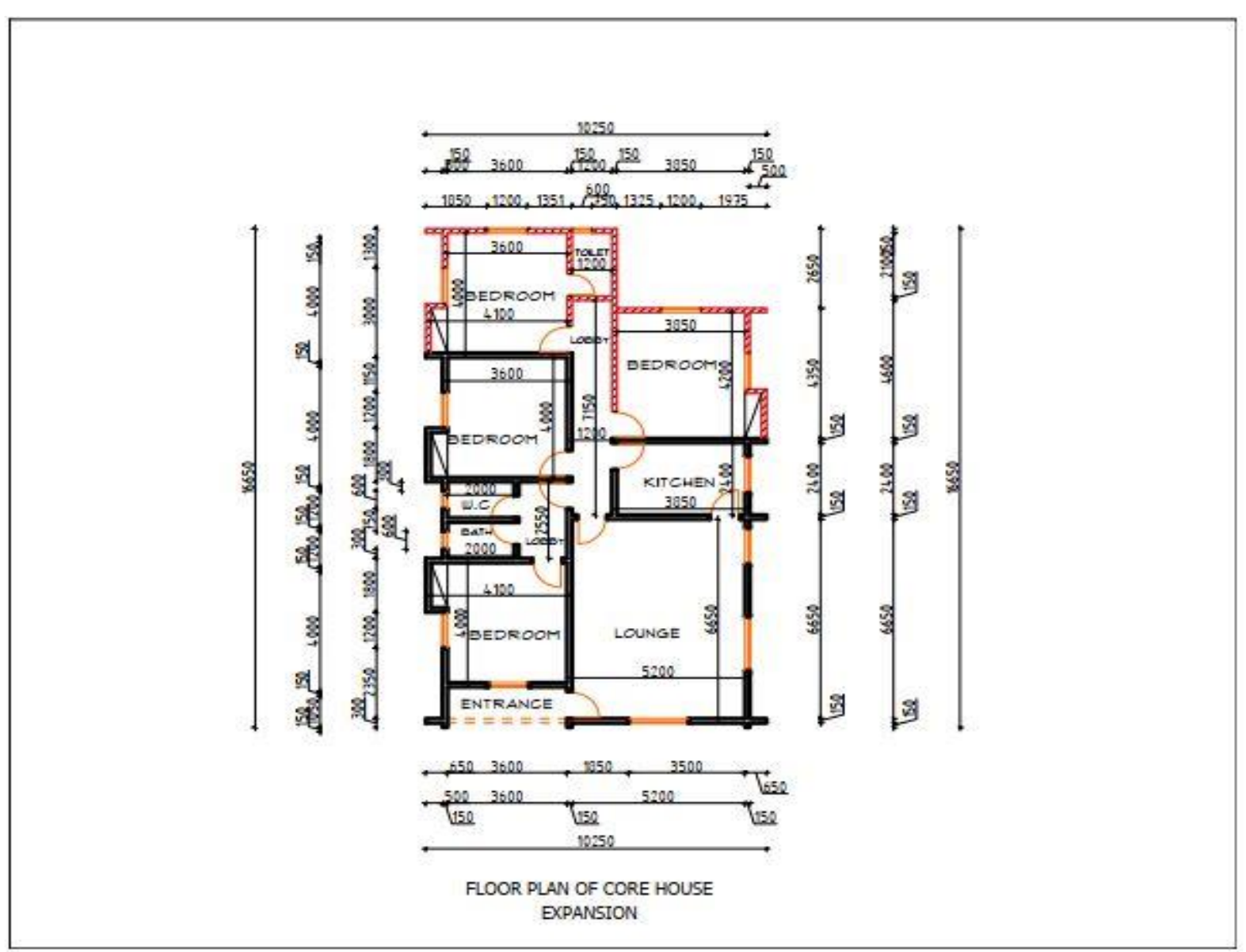

Figure 10: Floor plan for Core House Expansion, the Detached 2- bedroom bungalow (Core House) at AHOCOL Inner City Layout, Nkwelle, Awka (AHOCOL 4)

Source: Field Work (2017). Reproduced from Archival Records of Anambra State Housing Development Corporation, Awka.

Figure 10 is the floor plan for core house expansion of the Detached 2- bedroom bungalow (Core house) at AHOCOL Inner City Layout, Nkwelle, Awka (AHOCOL 4). 


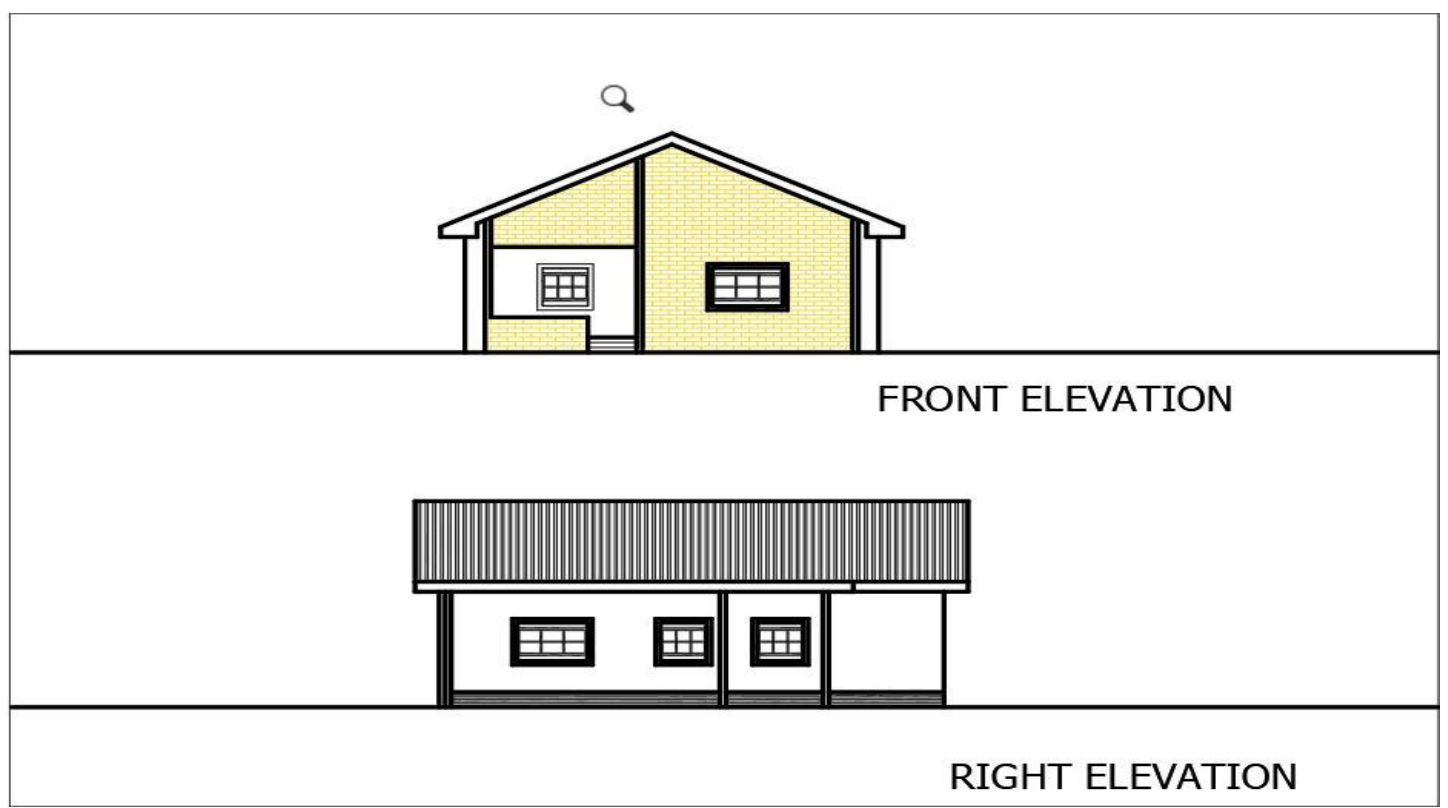

Figure 11: Front and Right Side Elevations of the Detached 2- bedroom bungalow (Core House) at AHOCOL Inner City Layout, Nkwelle, Awka (AHOCOL 4)

Figure 11 is the front and right side elevations of the Detached 2- bedroom bungalow (Core house) at AHOCOL Inner City Layout, Nkwelle, Awka (AHOCOL 4).

\section{(b) Photographic images}

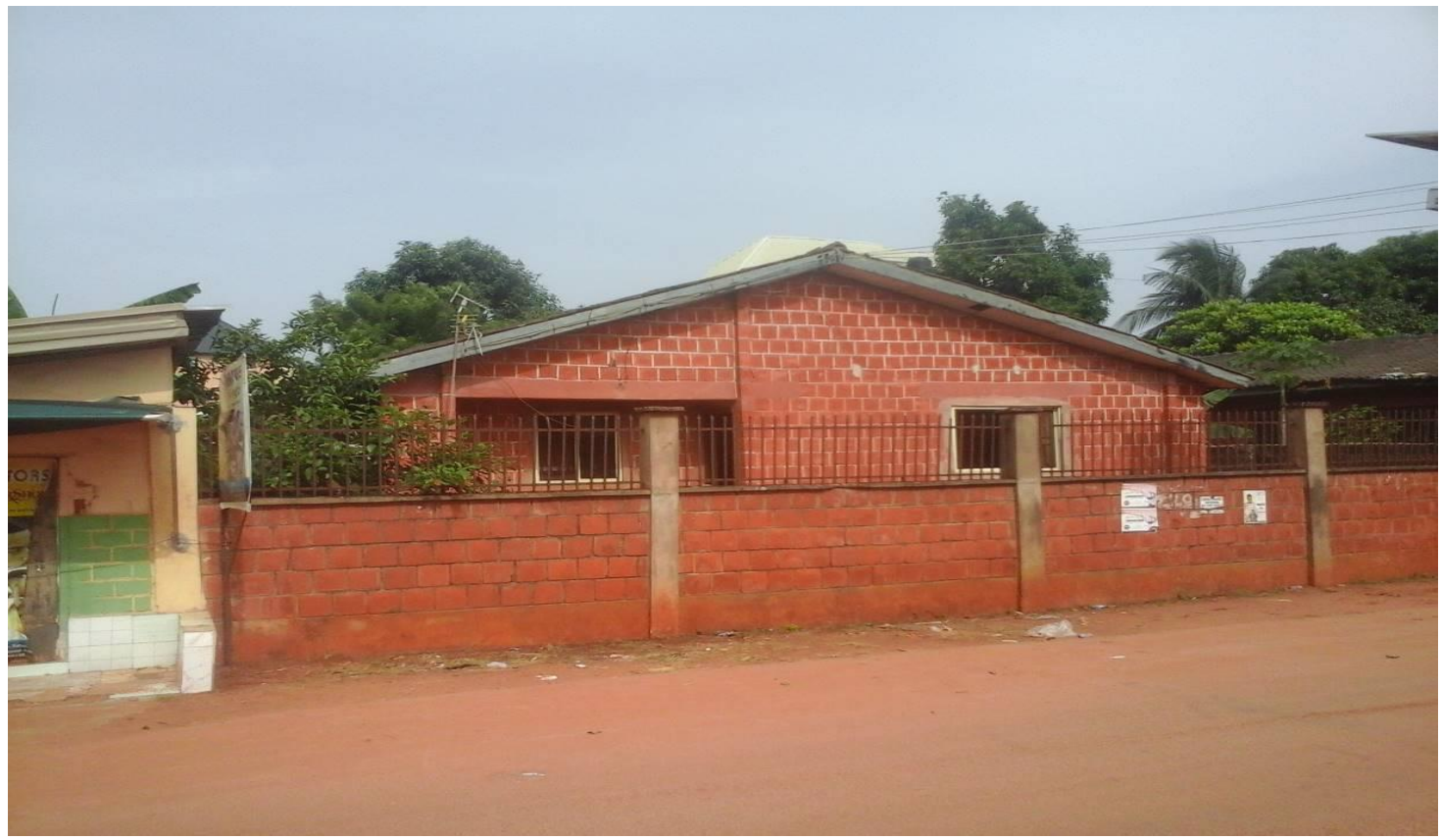

Plate 6: Detached 2- bedroom bungalow (Core House) at AHOCOL Inner City Layout, Nkwelle, Awka (AHOCOL 4) showing its appearance as a full-provision house rather than a partial-provision type (core house). 
(c) Result on asertaining the characteristic "flexibility in space use in architectural design" in the detached 2- bedroom bungalow at AHOCOL Inner City Layout, Nkwelle, Awka (AHOCOL 4)

\section{(i) Variable 1 - Flexibility in use of sitting room also for dining.}

The sitting room was designed for elastic use for sitting as well as eating as is done to portray flexibility in space use. This is because from Figures 9 and 10, it can be seen that no dining space distinct from the sitting room was provided. The prototype is rated Yes for this variable.

\section{(ii) Variable 2 - Flexibility in use of kitchen also for food storage}

The kitchen was designed for elastic use for cooking as well as food storage as is done to portray flexibility in space use. No separate food storage space was provided. This can be seen in Figures 9 and 10. The prototype is rated Yes for this variable.

\section{(iii) Variable 3 - Flexibility in sub-division of internal spaces after ocupation}

All of the internal spaces (sitting room, dining, kitchen, bedrooms, toilet and bathroom) were sub-divided with permanent walls prior to occupation,, as is shown in Figures 9 and 10. The floor plan did not indicate that some of the spaces were to be sub-divided after occupation at owners' finanancial convenience, which portrays flexibility in space use. The prototype is rated No for this variable. 
Prototype 4: Detached 1 - Bedroom bungalow (core house) at ASHDC Ngozika Housing Estate, Phase 1, Ikwodiaku, Awka (NGOZIKA 1)

(a) Architectural drawings

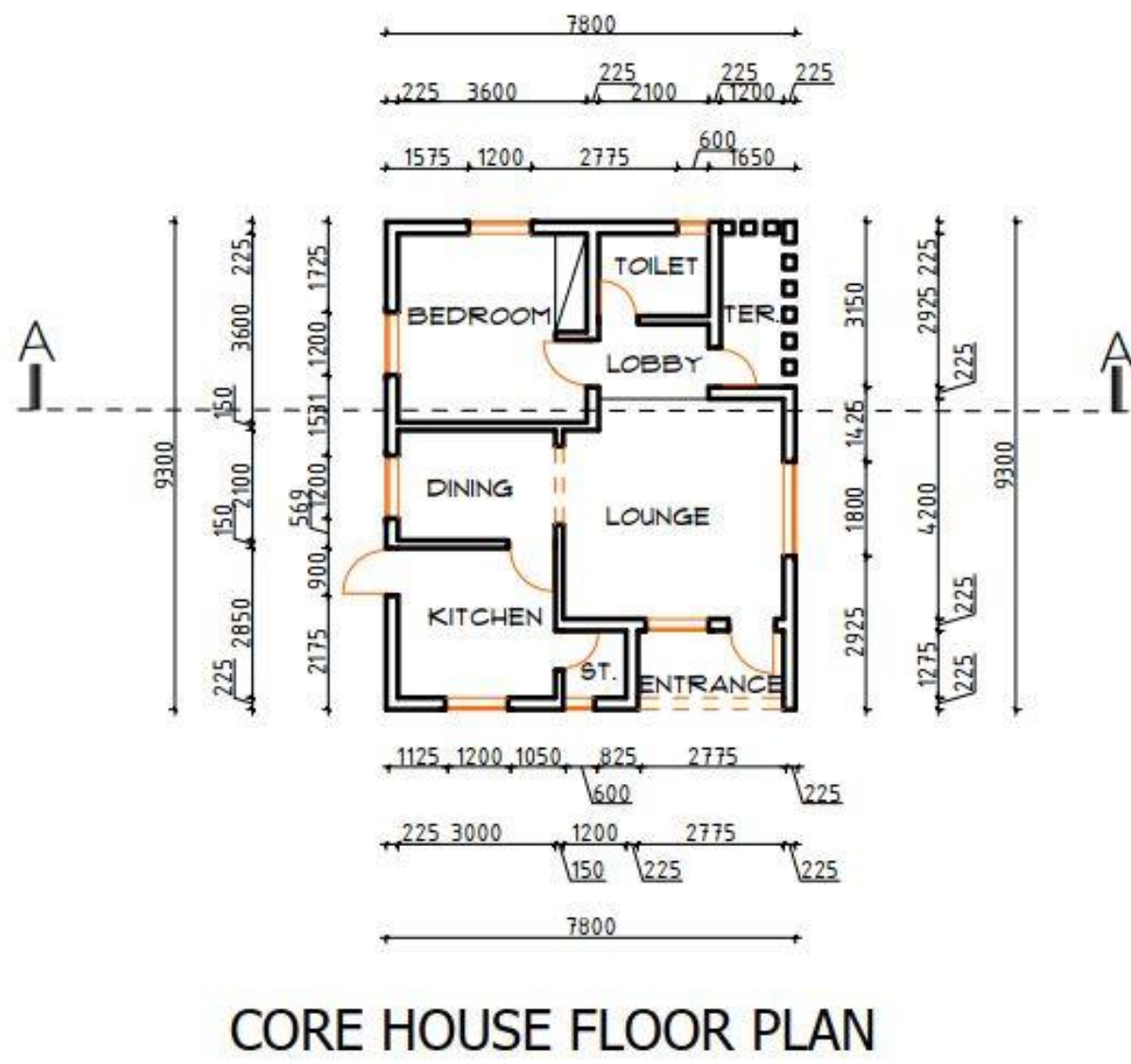

Figure 12: Floor Plan of the Detached 1- bedroom bungalow (Core House) at ASHDC Ngozika Housing Estate, Phase 1, Ikwodiaku, Awka (NGOZIKA 1)

Source: Field Work (2017). Reproduced from Archival Records of Anambra State Housing Development Corporation, Awka.

Figure 12 is the floor plan of the Detached 1- bedroom bungalow (Core House) at ASHDC Ngozika Housing Estate, Phase 1, Ikwodiaku, Awka (NGOZIKA 1). 


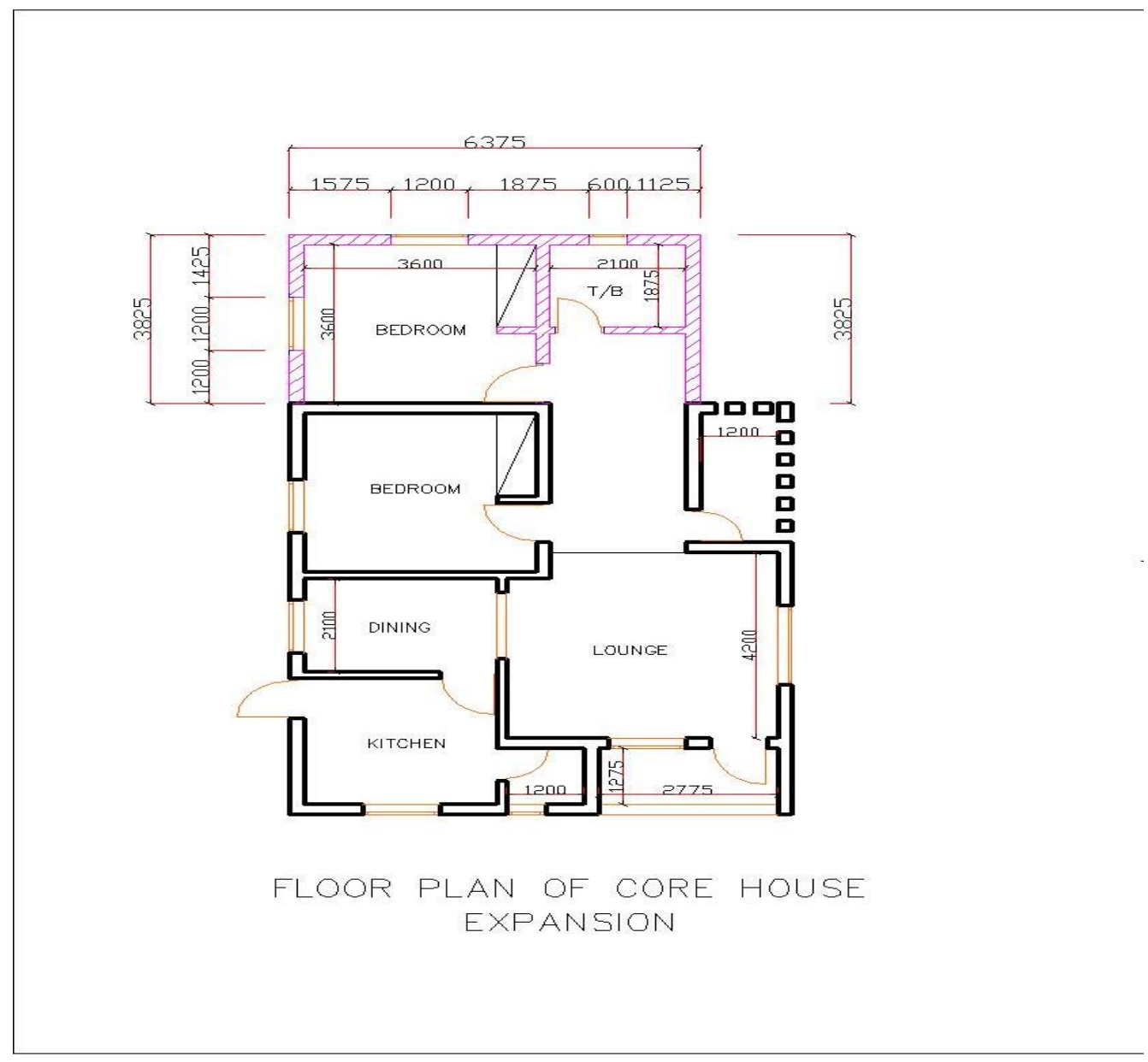

Figure 13: Floor Plan for Core House Expansion, the Detached 1- bedroom bungalow (Core House) at ASHDC Ngozika Housing Estate, Phase 1, Ikwodiaku, Awka (NGOZIKA 1)

Source: Field Work (2017). Reproduced from Archival Records of Anambra State Housing Development Corporation, Awka.

Figure 13 is the floor plan for Core House expansion of the Detached 1- bedroom bungalow (Core House) at ASHDC Ngozika Housing Estate, Phase 1, Ikwodiaku, Awka (NGOZIKA 1). 


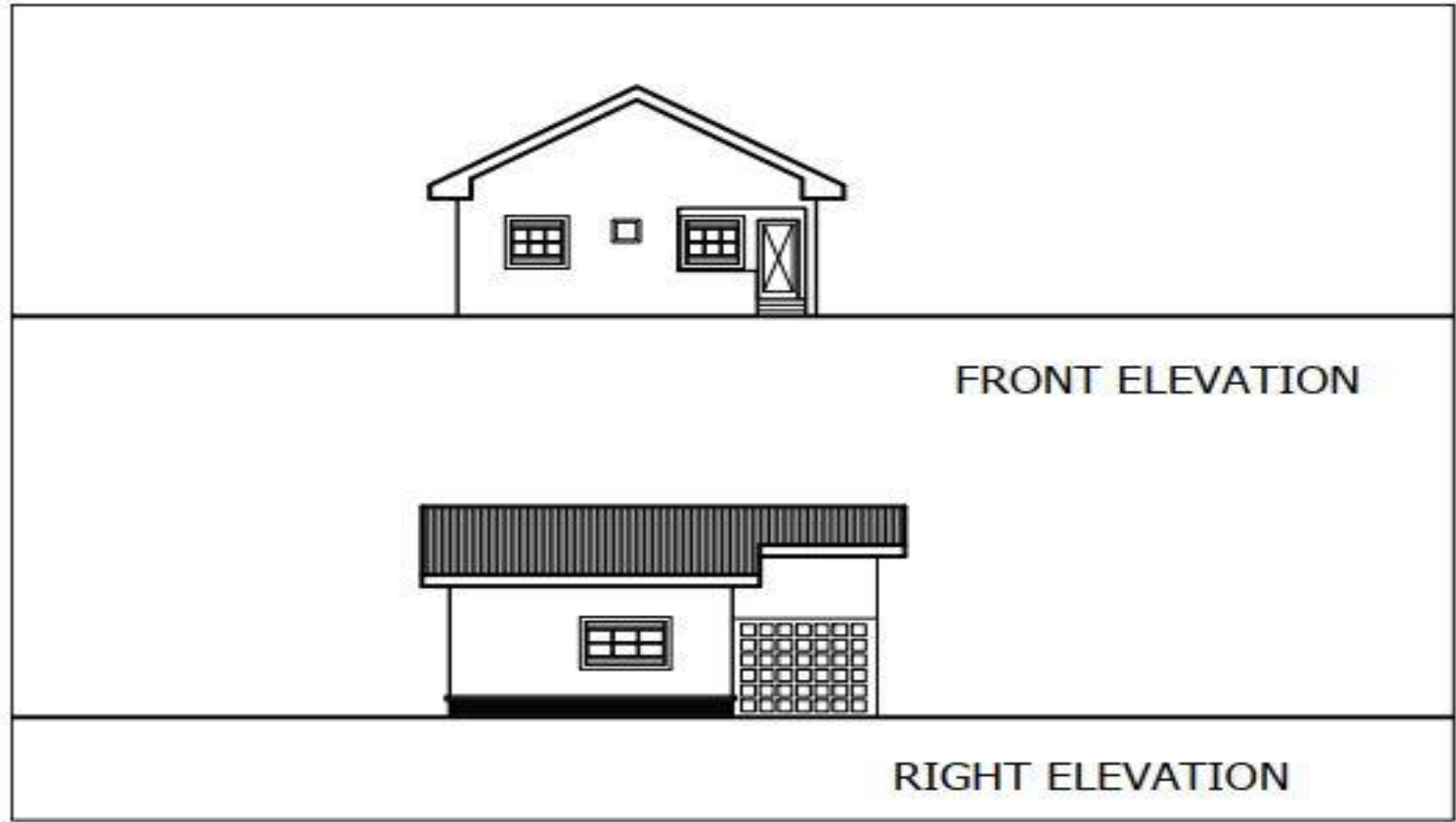

Figure 14: Front and Right Side Elevations of the Detached 1- bedroom bungalow (Core House) at ASHDC Ngozika Housing Estate, Phase 1, Ikwodiaku, Awka (NGOZIKA 1)

Source: Field Work (2017). Reproduced from Archival Records of Anambra State Housing Development Corporation, Awka.

Figure 14 is the front and right side elevations of the Detached 1- bedroom bungalow (Core House) at ASHDC Ngozika Housing Estate, Phase 1, Ikwodiaku, Awka (NGOZIKA 1).

(b) Photographic image

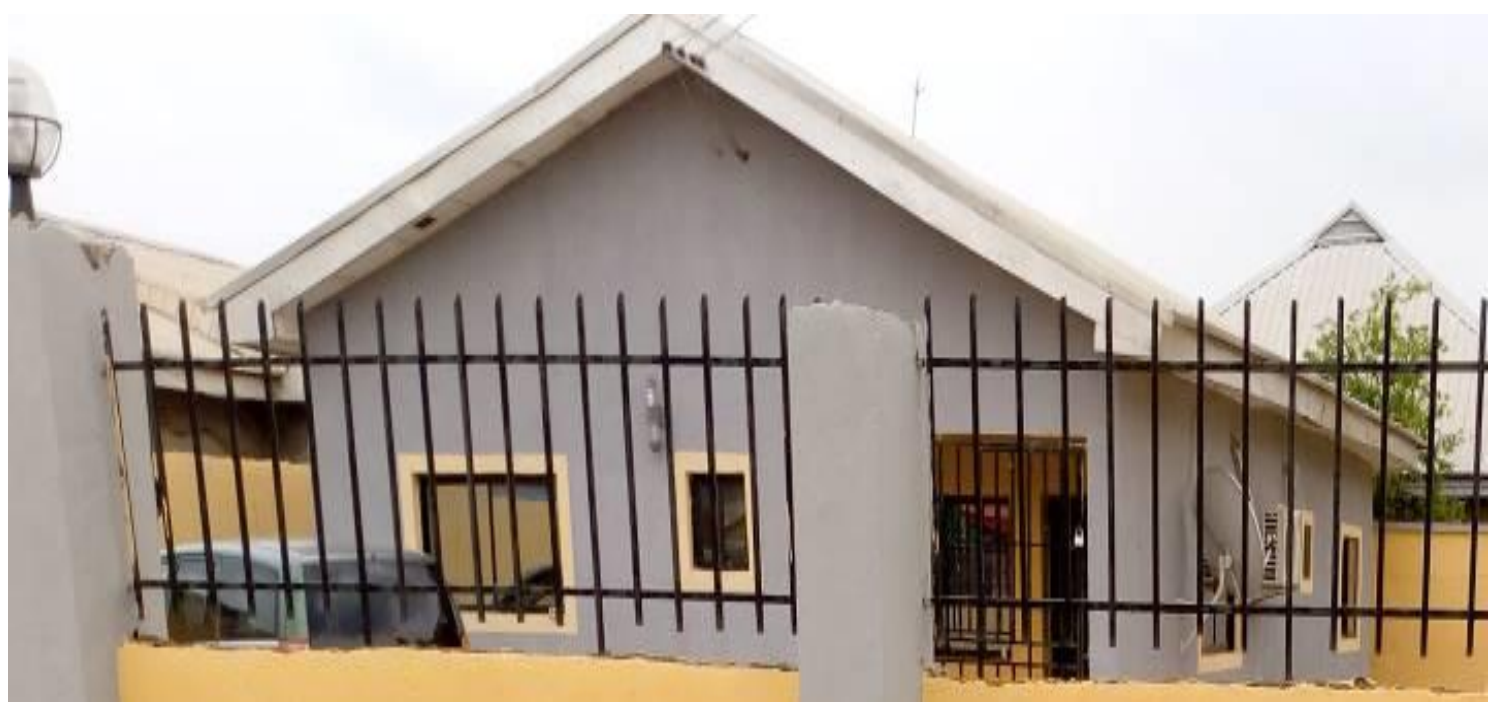

Plate 7: Detached 1- bedroom bungalow (Core House) at ASHDC Ngozika Housing Estate, Phase 1, Ikwodiaku, Awka (NGOZIKA 1) showing its appearance as a fullprovision house rather than a partial-provision type (core house). 
(c) Result on asertaining the characteristic "flexibility in space use in architectural design" in the Detached 1- bedroom bungalow at ASHDC Ngozika Housing Estate, Phase 1, Ikwodiaku, Awka (NGOZIKA 1)

(i) Variable 1 - Flexibility in use of sitting room also for dining.

The sitting room was not designed for elastic use for sitting as well as eating as is done to portray flexibility in space use. This is because from Figures 12 and 13, it can be seen that a semistructured and dedicated dining space distinct from the sitting room was provided. The prototype is rated No for this variable.

(ii) Variable 2 - Flexibility in use of kitchen also for food storage

The kitchen was not designed for elastic use for cooking as well as food storage as is done to portray flexibility in space use, A separate food storage space was provided. This can be seen in Figures 12 and 13. The prototype is rated No for this variable.

(iii) Variable 3 - Flexibility in sub-division of internal spaces after occupation

All of the internal spaces (sitting room, dining, kitchen, bedrooms, toilet and bathroom) were subdivided with permanent walls prior to occupation, as is shown in Figures 12 and 13. The floor plan did not indicate that some of the spaces were to be sub-divided after occupation at owners' finanancial convenience, which portrays flexibility in space use. The prototype is rated No for this variable.

Prototype 5: Detached 2- bedroom bungalow at ASHDC Ngozika Housing Estate, Phase 1, Ikwodiaku, Awka (NGOZIKA 2)

(a) Architectural drawings

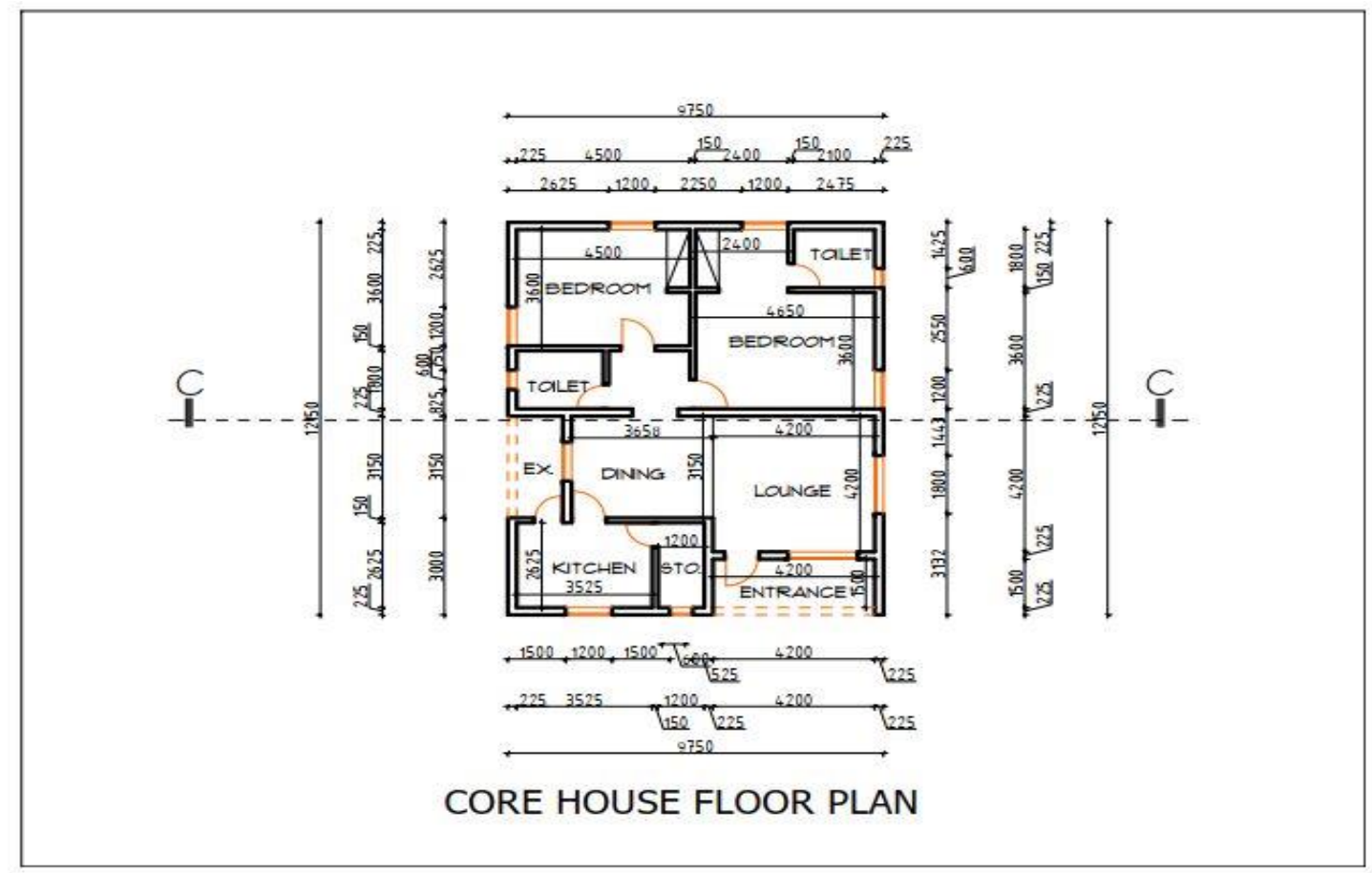

Figure 15: Floor Plan of the Detached 2- bedroom Bungalow (Core House) at ASHDC Ngozika Housing Estate, Phase 1, Ikwodiaku, Awka (NGOZIKA 1)

Source: Field Work (2017). Reproduced from Archival Records of Anambra State Housing Development Corporation, Awka. 
Figure 15 is the floor plan of the Detached 2-bedroom bungalow (Core House) at ASHDC Ngozika Housing Estate, Phase 1, Ikwodiaku, Awka (NGOZIKA 1).

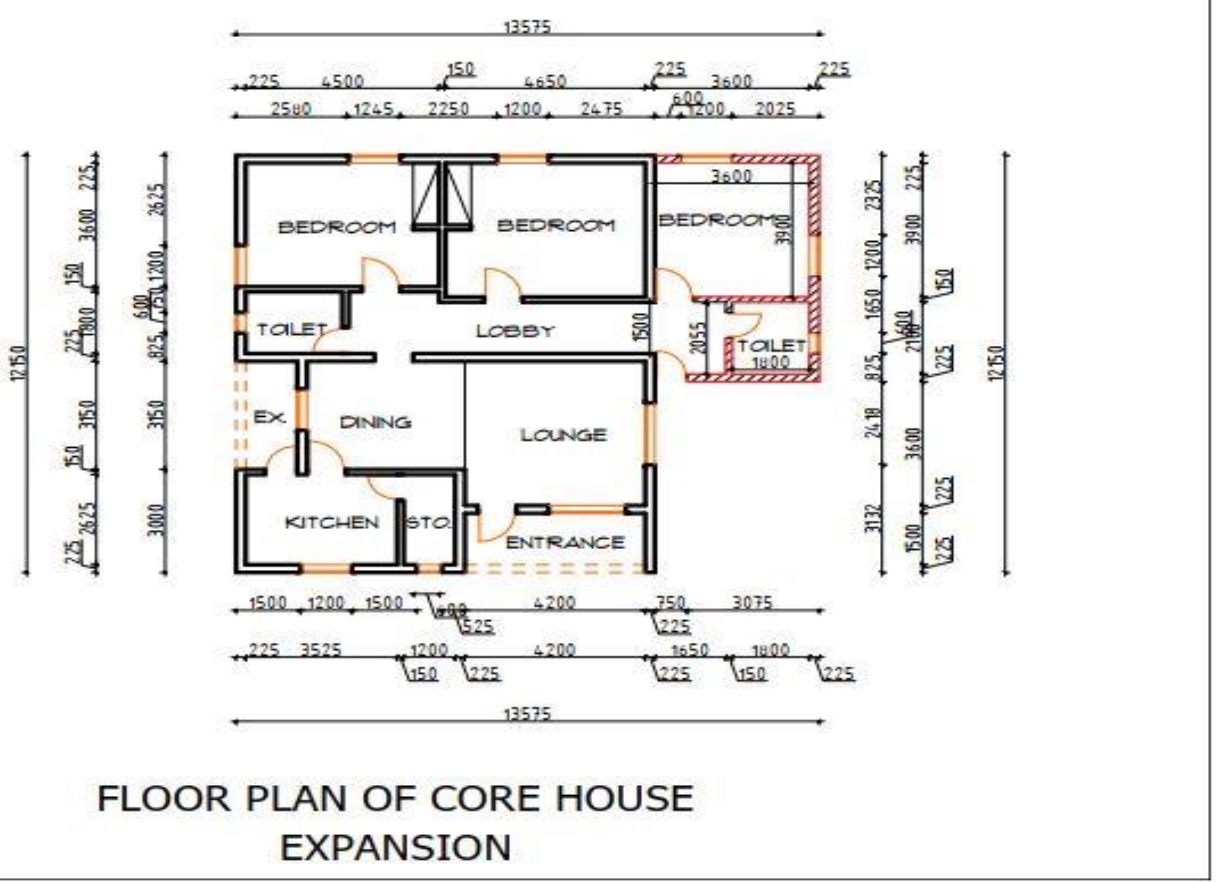

Figure 16: Floor plan for Core House Expansion, the Detached 2- bedroom bungalow (Core House) at ASHDC Ngozika Housing Estate, Phase 1, Ikwodiaku, Awka (NGOZIKA 1)

Source: Field Work (2017). Reproduced from Archival Records of Anambra State Housing Development Corporation, Awka.

Figure 16 is the floor plan for Core House Expansion of the Detached 2- bedroom bungalow (Core House) at ASHDC Ngozika Housing Estate, Phase 1, Ikwodiaku, Awka (NGOZIKA 1). 
(b) Photographic image

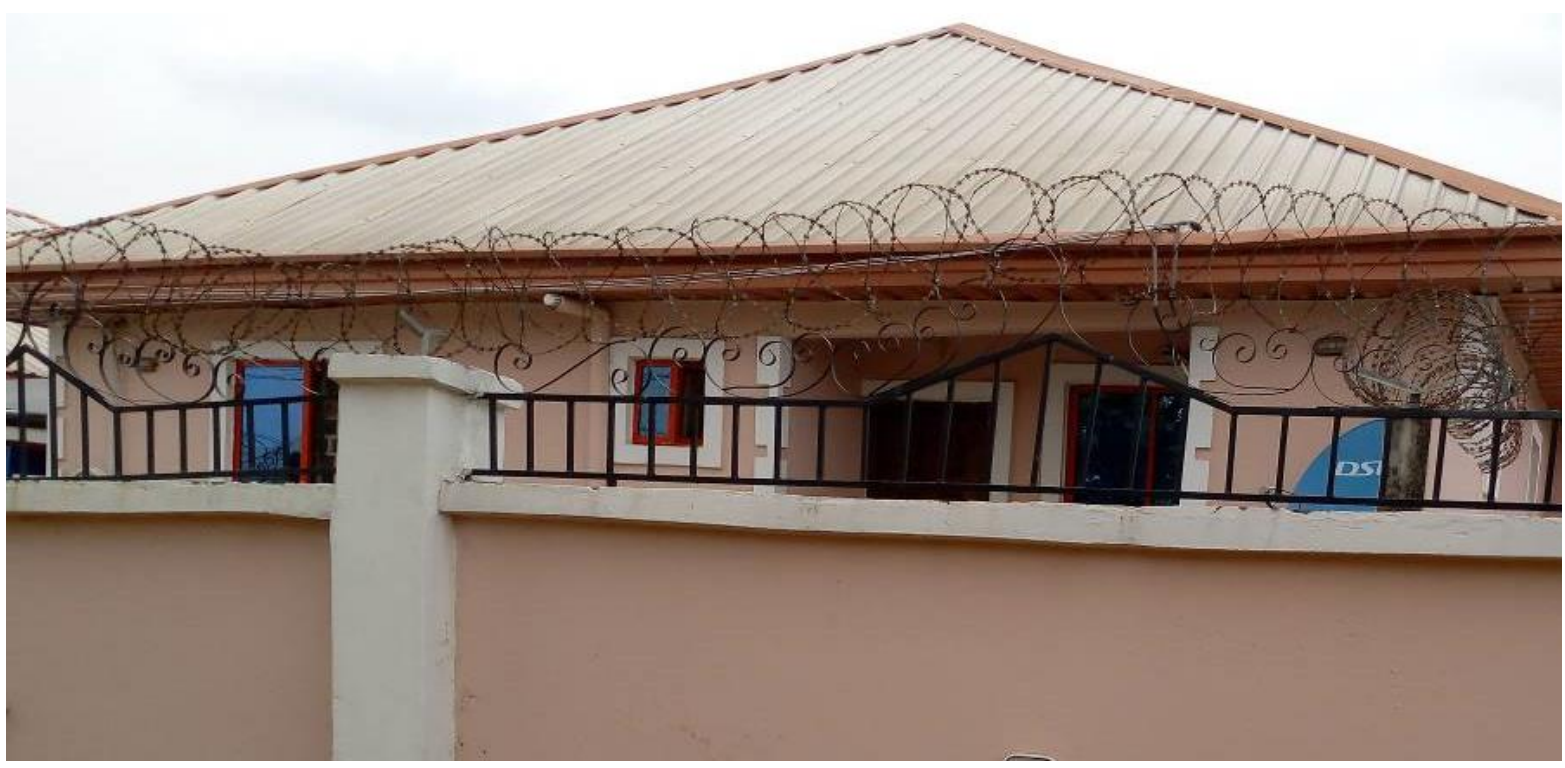

Plate 8: Detached 2- bedroom bungalow (Core House) at ASHDC Ngozika Housing Estate, Phase 1, Ikwodiaku, Awka (NGOZIKA 1) showing its appearance as a fullprovision house rather than a partial-provision type (core house).

(c) Result on asertaining the characteristic "flexibility in space use in architectural design" in the Detached 2- bedroom bungalow at ASHDC Ngozika Housing Estate, Phase 1, Ikwodiaku, Awka (NGOZIKA 2)

(i) Variable 1 - Flexibility in use of sitting room also for dining.

The sitting room was not designed for elastic use for sitting as well as eating as is done to portray flexibility in space use. This is because from Figures 15 and 16 it can be seen that a semi-structured and dedicated dining space distinct from the sitting room was provided. The prototype is rated No for this variable.

\section{ii) Variable 2 - Flexibility in use of kitchen also for food storage}

The kitchen was not designed for elastic use for cooking as well as food storage as is done to portray flexibility in space use, A separate food storage space was provided. This can be seen in Figures 15 and 16. The prototype is rated No for this variable.

\section{(iii) Variable 3 - Flexibility in sub-division of internal spaces after occupation}

All of the internal spaces (sitting room, dining, kitchen, bedrooms, toilets) were sub-divided with permanent walls prior to occupation, as is shown in Figures 15 and 16. The floor plan did not indicate that some of the spaces were to be sub-divided after occupation at owners' finanancial convenience, which portrays flexibility in space use. The prototype is rated No for this variable. 
African Journal of Economics and Sustainable Development

ISSN: 2689-5080

Volume 4, Issue 2, 2021 (pp. 39-85)

www.abjournals.org

Prototype 6: Detached 3- bedroom bungalow at ASHDC Ngozika Housing Estate, Phase 1, Ikwodiaku, Awka (NGOZIKA 3)

(a) Architectural drawing

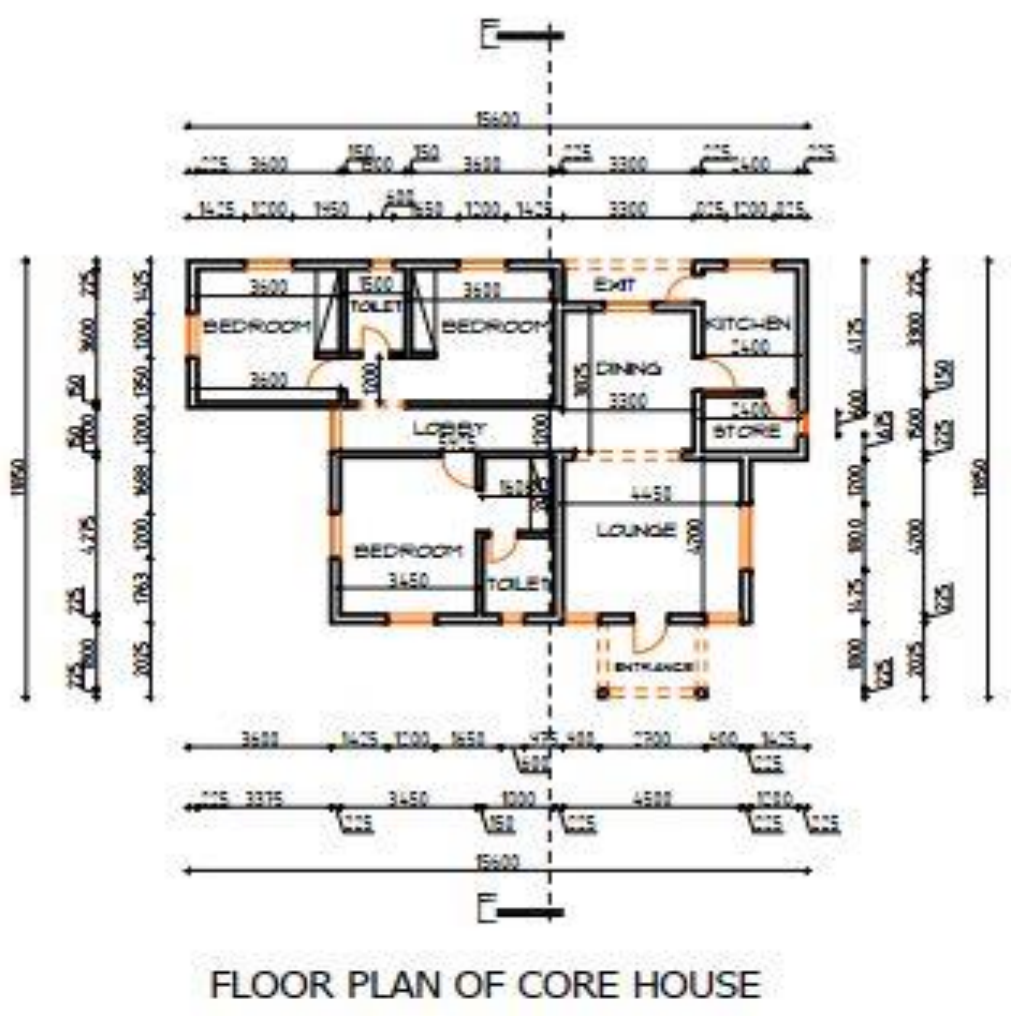

Figre 17: Floor Plan of the Detached 3- bedroom bungalow (Core House) at ASHDC Ngozika Housing Estate, Phase 1, Ikwodiaku, Awka (NGOZIKA 3)

Source: Field Work (2017). Reproduced from Archival Records of Anambra State Housing Development Corporation, Awka.

Figure 17 is the floor plan of the Detached 3-bedroom bungalow (Core House) at ASHDC) Ngozika Housing Estate, Phase 1, Ikwodiaku, Awaka (NGOZIKA 1). 


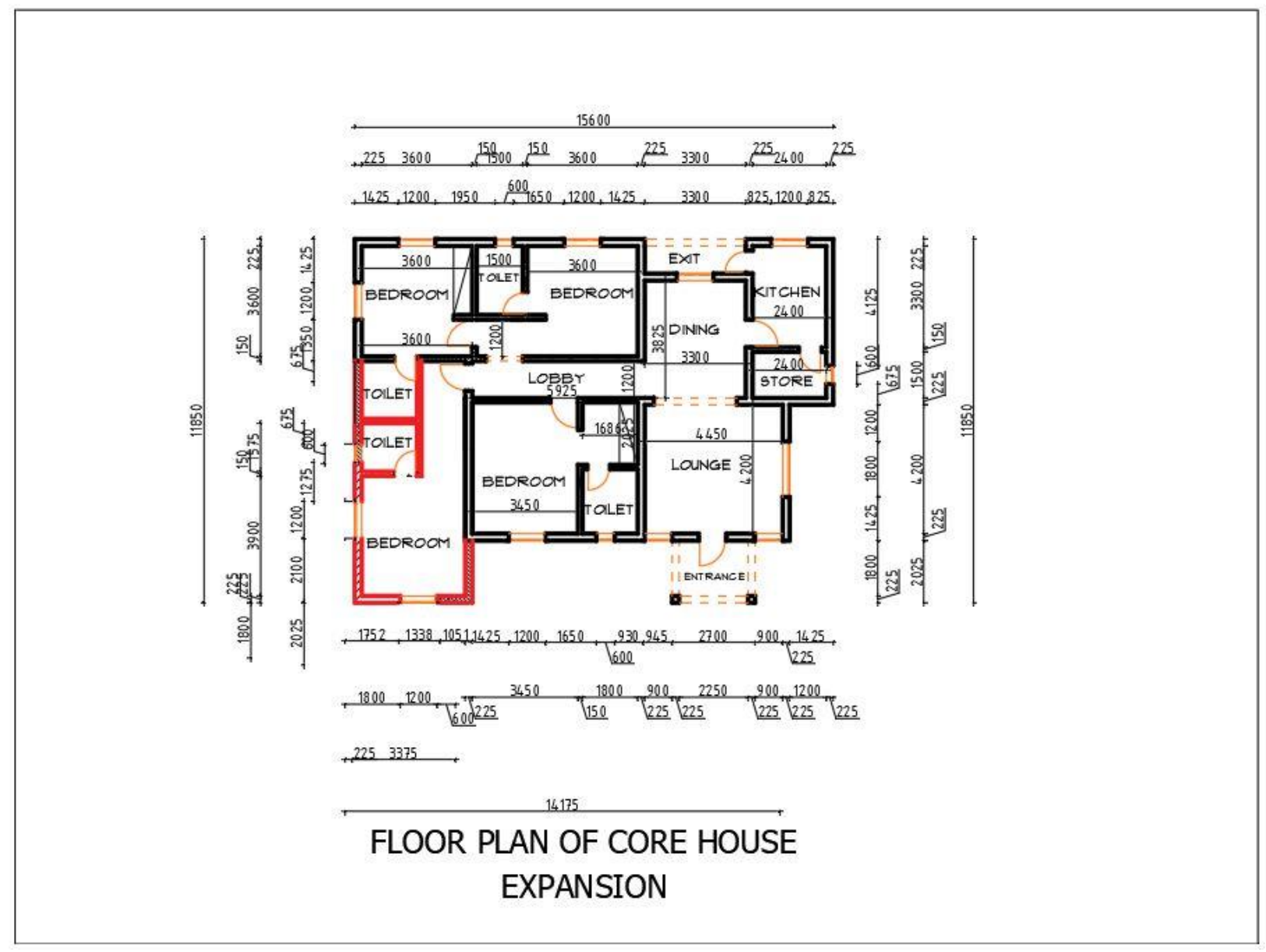

Figure 18: Floor plan for Core House Expansion, the Detached 3- bedroom bungalow (Core House) at ASHDC Ngozika Housing Estate, Phase 1, Ikwodiaku, Awka (NGOZIKA 3)

Source: Field Work (2017). Reproduced from Archival Records of Anambra State Housing Development Corporation, Awka.

Figure 18 is the floor plan core house expansion of the Detached 3-bedroom bungalow (Core House) at ASHDC Ngozika Housing Estate, Phase 1, Ikwodiaku, Awaka (NGOZIKA 1). 


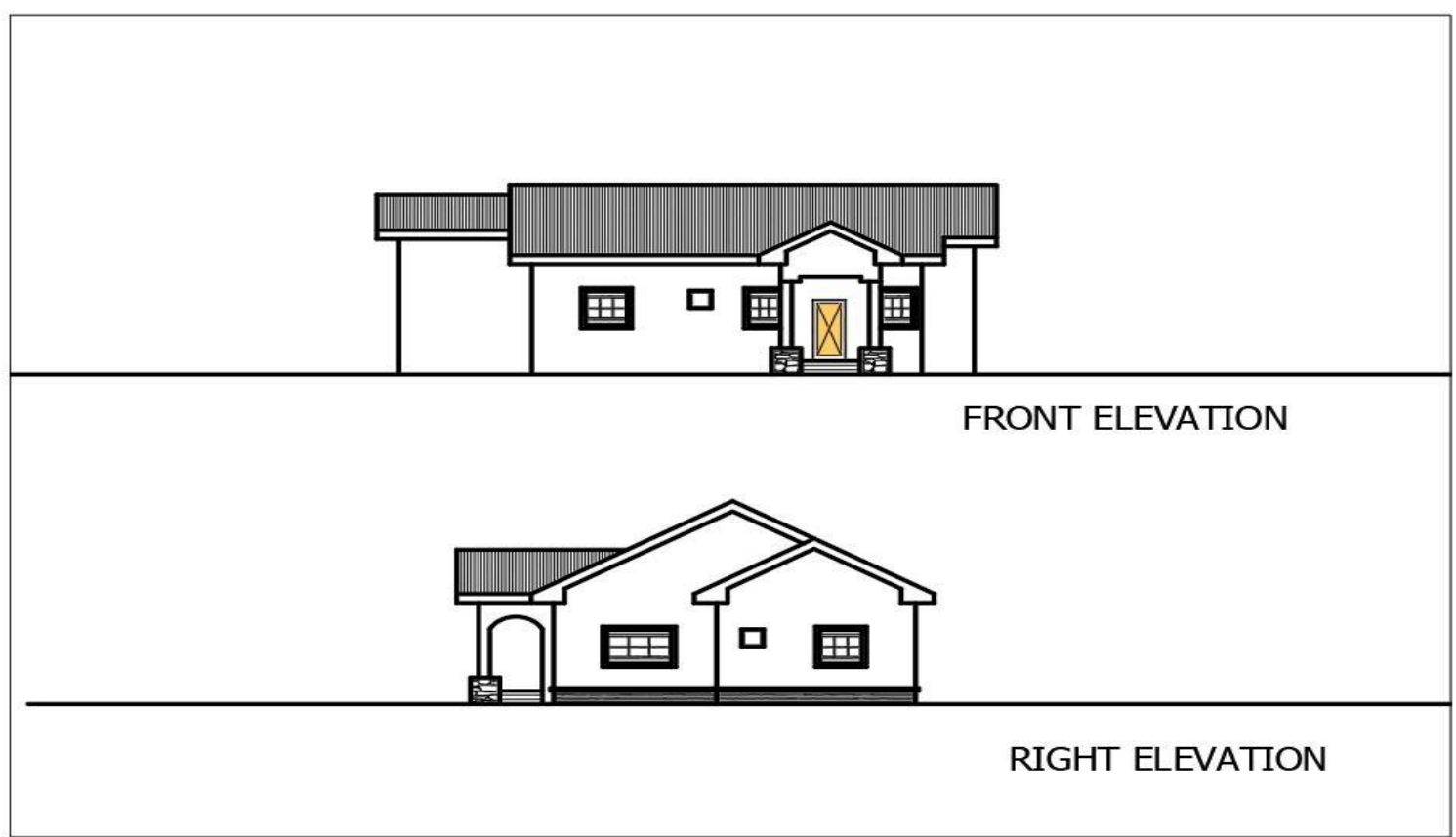

Figure 19: Front and Right Side Elevations of the Detached 3- bedroom Bungalow (Core House) at ASHDC Ngozika Housing Estate, Phase 1, Ikwodiaku, Awka (NGOZIKA 3)

Source: Field Work (2017). Reproduced from Archival Records of Anambra State Housing Development Corporation, Awka.

Figure 19 is the floor plan core house expansion of the Detached 3-bedroom bungalow (Core House) at ASHDC Ngozika Housing Estate, Phase 1, Ikwodiaku, Awaka (NGOZIKA 1).

(b) Photographic image

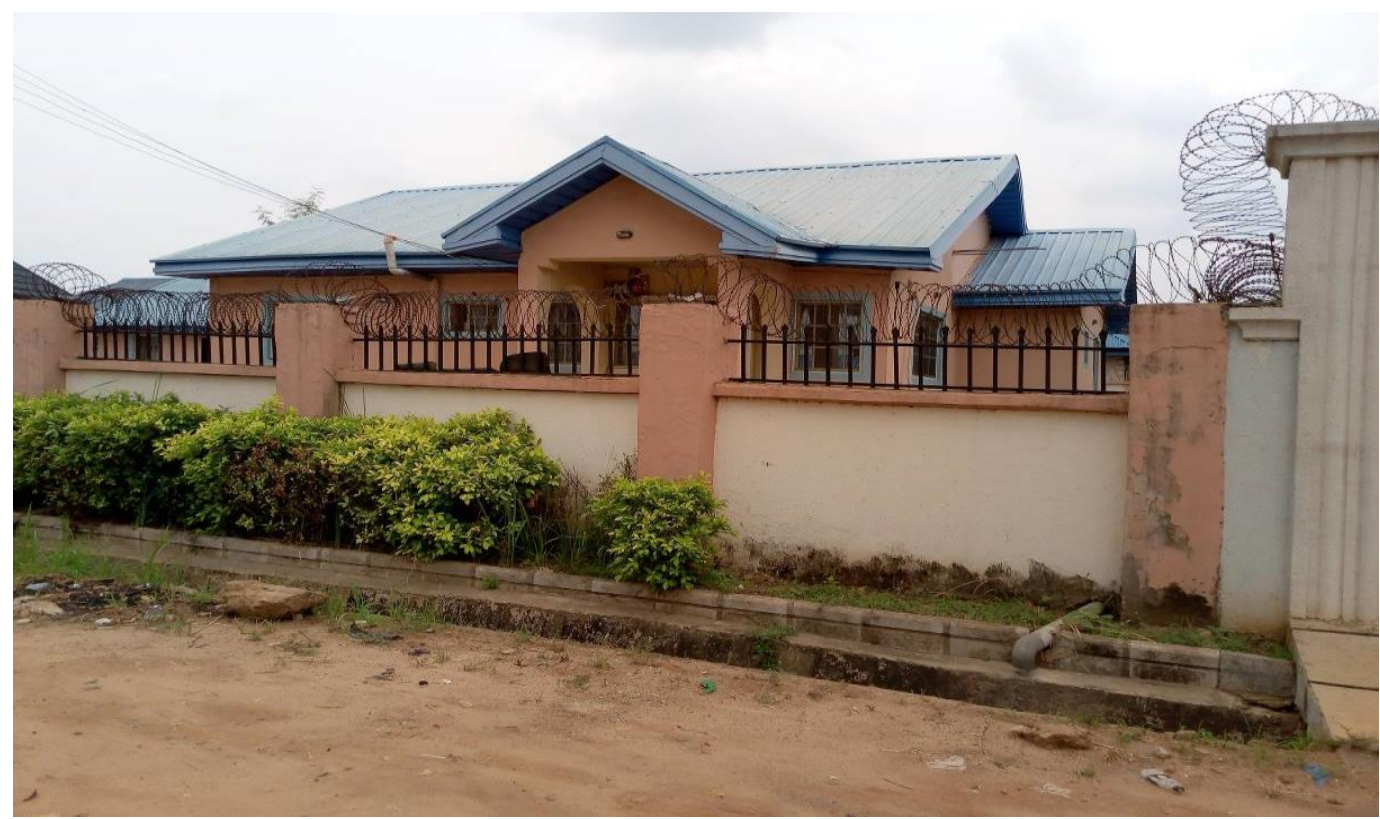

Plate 8: Detached 3 - bedroom bungalow (Core House) at ASHDC Ngozika Housing Estate, Phase 1, Ikwodiaku, Awka (NGOZIKA 3) 
(c) Result on asertaining the characteristic "flexibility in space use in architectural design" in the Detached 3- bedroom bungalow at ASHDC Ngozika Housing Estate, Phase 1, Ikwodiaku, Awka (NGOZIKA 3)

\section{(i) Variable 1 - Flexibility in use of sitting room also for dining.}

The sitting room was not designed for elastic use for sitting as well as eating as is done to portray flexibility in space use. This is because from Figures 17 and 18 it can be seen that a semi-structured and dedicated dining space distinct from the sitting room was provided. The prototype is rated No for this variable.

\section{(ii) Variable 2 - Flexibility in use of kitchen also for food storage}

The kitchen was not designed for elastic use for cooking as well as food storage as is done to portray flexibility in space use, A separate food storage space was provided. This can be seen in Figures 17 and 18. The prototype is rated No for this variable.

\section{(iv) Variable 3 - Flexibility in sub-division of internal spaces after occupation}

All of the internal spaces (sitting room, dining, kitchen, bedrooms, toilet and bathroom) were sub-divided with permanent walls prior to occupation, as is shown in Figures 17 and 18. The floor plan did not indicate that some of the spaces were to be sub-divided after occupation at owners' finanancial convenience, which portrays flexibility in space use. The prototype is rated No for this variable.

Below is the summary of the results on ascertaining flexibility in space use in the architectural drawings of the existing core house prototypes

\section{(i) Semi-detached 3- bedroom bungalow (AHOCOL 1 and AHOCOL 2)}

The three variables used to measure flexibility in space use, namely: (i) flexibility in use of sitting room also for dining; (ii) flexibility in use of kitchen also for food storage; and (iii) flexibility in sub-division of internal spaces after ocupation have a rating of No, Yes and No respectively. This prototype, Semi-detached 3- bedroom bungalow (AHOCOL 1 and AHOCOL 2) was therefore rated No for flexibility in space use.

(ii) Detached 3- bedroom bungalow at AHOCOL Oganiru Housing Estate, Agu-Awka (AHOCOL 3)

The three variables used to measure flexibility in space use, namely: (i) flexibility in use of sitting room also for dining; (ii) flexibility in use of kitchen also for food storage; and (iii) flexibility in sub-division of internal spaces after ocupation have a rating of No, No and No respectively. This prototype, Detached 3- bedroom bungalow at AHOCOL Oganiru Housing Estate, Agu-Awka (AHOCOL 3) was therefore rated No for flexibility in space use.

(iii) Detached 2- bedroom bungalow at AHOCOL Inner City Layout, Nkwelle, Awka (AHOCOL 4)

The three variables used to measure flexibility in space use, namely: (i) flexibility in use of sitting room also for dining; (ii) flexibility in use of kitchen also for food storage; and (iii) flexibility in sub-division of internal spaces after ocupation have a rating of Yes, Yes and No 
respectively. This prototype, Detached 2- bedroom bungalow at AHOCOL Inner City Layout, Nkwelle, Awka (AHOCOL 4) was therefore rated Yes for flexibility in space use.

\section{(iv) Detached 1- bedroom bungalow at ASHDC Ngozika Housing Estate, Phase 1, Ikwodiaku, Awka (NGOZIKA 1)}

The three variables used to measure flexibility in space use, namely: (i) flexibility in use of sitting room also for dining; (ii) flexibility in use of kitchen also for food storage; and (iii) flexibility in sub-division of internal spaces after ocupation have a rating of No, No and No respectively. This prototype, Detached 1- bedroom bungalow at ASHDC Ngozika Housing Estate, Awka (NGOZIKA 1) was therefore rated No for flexibility in space use.

\section{(v) Detached 2- bedroom bungalow at ASHDC Ngozika Housing Estate, Phase 1, Ikwodiaku, Awka (NGOZIKA 2)}

The three variables used to measure flexibility in space use, namely: (i) flexibility in use of sitting room also for dining; (ii) flexibility in use of kitchen also for food storage; and (iii) flexibility in sub-division of internal spaces after ocupation have a rating of No, No and No respectively. This prototype, Detached 2- bedroom bungalow at ASHDC Ngozika Housing Estate, Awka (NGOZIKA 2) was therefore rated No for flexibility in space use.

(vi) Detached 3- bedroom bungalow at ASHDC Ngozika Housing Estate, Phase 1, Ikwodiaku, Awka (NGOZIKA 3)

The three variables used to measure flexibility in space use, namely: (i) flexibility in use of sitting room also for dining; (ii) flexibility in use of kitchen also for food storage; and (iii) flexibility in sub-division of internal spaces after ocupation have a rating of No, No and No respectively. This prototype, Detached 3- bedroom bungalow at ASHDC Ngozika Housing Estate, Awka (NGOZIKA 3) was therefore rated No for flexibility in space use. Additionally, the core house prototypes studied seem more like full provision/ finished houses rather than core houses.

The summary of the results on ascertaining if flexibility in space use is reflected in the architectural designs of the existing public core housing schemes in Anambra State is shown in Table 4. The result indicates flexibility in space use being reflected only in 1 out of the 7 existing public core house prototypes in Anambra State studied. The attribute was not reflected in the majority ( 6 of the prototypes). Out of a total 230 also, flexibility in space use was reflected only in 3 of them. It was not reflected in the architectural designs of the following prototypes: (i) semi-detached 3-bedroom bungalow at AHOCOL Phase 1 (AHOCOL 1) - 0 out of 19 dwelling units; (ii) semi-detached 3-bedroom bungalow at AHOCOL Phase 2 (AHOCOL 2) - 0 out of 42 dwelling units; (iii) detached 3-bedroom bungalow at AHOCOL Oganiru Housing Estate, Agu-Awka (AHOCOL 3) - 0 out of 26 dwelling units; (iv) detached 1-bedroom bungalow at ASHDC Ngozika Housing Estate, Phase 1, Ikwodiaku, Awka, (NGOZIKA 1) - 0 out of 49 dwelling units; (v) detached 2bedroom bungalow at ASHDC Ngozika Housing Estate, Phase 1, Ikwodiaku, Awka, (NGOZIKA 2) - 0 out of 45 dwelling units; and (vi) detached 3-bedroom bungalow at ASHDC Ngozika Housing Estate, Phase 1, Ikwodiaku, Awka, (NGOZIKA 3) - 0 out of 46 dwelling units. It is only in the detached 2-bedroom bungalow at AHOCOL Inner City Layout, Nkwelle, Awka (AHOCOL 4) that flexibility in space use was reflected -3 out of 3 dwelling units. Futhermore, as can be seen from the Figures and plates displayed in the 
results, the prototypes appear more like full-provision/finished houses instead of partialprovision types where core houses belong.

Table 4: Summary of Result on Ascertaining if Flexibility in Space Use is Reflected in the Architectural Designs of the Existing Public Core Housing Schemes in Anambra State.

\begin{tabular}{|c|c|c|c|c|}
\hline $\mathbf{S} / \mathbf{N}$ & Prototype & $\begin{array}{c}\text { Ratings for the } 3 \\
\text { Variables for } \\
\text { Measuring Flexibility } \\
\text { in Space Use in } \\
\text { Architectural Design }\end{array}$ & $\begin{array}{r}\text { Nu } \\
\text { Pro } \\
\text { not R } \\
\text { Spac } \\
\end{array}$ & $\begin{array}{l}\text { nber of Core House } \\
\text { otypes Reflecting or } \\
\text { eflecting Flexibility in } \\
\text { Use in Architectural } \\
\text { Design }\end{array}$ \\
\hline 1. & $\begin{array}{l}\text { Semi-detached } \\
\text { bedroom at AHOCOL } 1\end{array}$ & $\begin{array}{l}\text { No, Yes, No } \\
\quad \text { NO }\end{array}$ & $\begin{array}{l}\text { No } \\
19\end{array}$ & $\begin{array}{l}\text { Yes } \\
0\end{array}$ \\
\hline 2. & $\begin{array}{l}\text { Semi-detached } \\
\text { bedroom at AHOCOL } 2\end{array}$ & $\begin{array}{l}\text { No, No, No } \\
\text { NO }\end{array}$ & 42 & 0 \\
\hline 3. & $\begin{array}{l}\text { Detached 3-bedroom at } \\
\text { AHOCOL } 3\end{array}$ & $\begin{array}{l}\text { No, No, No } \\
\text { NO }\end{array}$ & 26 & 0 \\
\hline 4. & $\begin{array}{l}\text { Detached 2-bedroom at } \\
\text { AHOCOL } 4\end{array}$ & $\begin{array}{l}\text { Yes, Yes, No } \\
\text { YES }\end{array}$ & 0 & 3 \\
\hline 5. & $\begin{array}{l}\text { Detached 1-bedroom at } \\
\text { NGOZIKA } \\
\text { (NGOZIKA 1) }\end{array}$ & $\begin{array}{c}\text { No, No, No } \\
\text { NO }\end{array}$ & 49 & 0 \\
\hline 6. & $\begin{array}{l}\text { Detached 3-bedroom at } \\
\text { NGOZIKA } \\
\text { (NGOZIKA 3) }\end{array}$ & $\begin{array}{l}\text { No, No, No } \\
\quad \text { NO }\end{array}$ & 45 & 0 \\
\hline 7. & $\begin{array}{l}\text { Detached 3-bedroom at } \\
\text { NGOZIKA } \\
\text { (NGOZIKA 3) }\end{array}$ & $\begin{array}{l}\text { No, No, No } \\
\quad \text { NO }\end{array}$ & 46 & 0 \\
\hline & Total & & 227 & 3 \\
\hline
\end{tabular}

Source: Field Work (2017) 


\section{Findings}

\section{Objective 1: to review literature explaining what constitutes flexibility in space use in architectural design in relation to core housing affordability.}

In the literature review section in 2.3 flexibility in space use in architectural design in relation to core housing affordability has been explained to incorporate: (i) flexibility in use of sitting room also for dining; (ii) flexibility in use of kitchen also for food storage; and (iii) flexibility in sub-division of internal spaces after occupation. In relation to core housing affordability it has been shown that this attribute is crucial in fostering affordability of core housing schemes. Therefore it is the finding of this study that: (i) flexibility in use of sitting room also for dining; (ii) flexibility in use of kitchen also for food storage; and (iii) flexibility in sub-division of internal spaces after occupation constitute flexibility in space use in architectural design in relation to core housing affordability and that the attribute promotes core housing affordability.

\section{Objective 2: to ascertain if flexibility in space use is reflected in the architectural designs of the existing public core housing schemes in Anambra State}

The results of the study show that out of the 7 existing public core house prototypes in Anambra State studied, flexibility in space use in architectural design was found not reflected in the majority (6 numbers) having a total of 227 out of the 230 prototypes studied. The prototypes that do not have flexibility in space use reflected in their architectural designs and the number of dwelling units are: (i) semi-detached 3-bedroom bungalow at AHOCOL Phase 1 (AHOCOL 1) - 0 out of 19 dwelling units; (ii) semi-detached 3-bedroom bungalow at AHOCOL Phase 2 (AHOCOL 2) - 0 out of 42 dwelling units; (iii) detached 3-bedroom bungalow at AHOCOL Oganiru Housing Estate, Agu-Awka (AHOCOL 3) - 0 out of 26 dwelling units; (iv) detached 1-bedroom bungalow at ASHDC Ngozika Housing Estate, Phase 1, Ikwodiaku, Awka, (NGOZIKA 1) - 0 out of 49 dwelling units; (v) detached 2bedroom bungalow at ASHDC Ngozika Housing Estate, Phase 1, Ikwodiaku, Awka, (NGOZIKA 2) - 0 out of 45 dwelling units; and (vi) detached 3-bedroom bungalow at ASHDC Ngozika Housing Estate, Phase 1, Ikwodiaku, Awka, (NGOZIKA 3) - 0 out of 46 dwelling units. It is only in one of the prototypes, the detached 2-bedroom bungalow at AHOCOL Inner City Layout, Nkwelle, Awka (AHOCOL 4) that flexibility in space use in architectural design was found reflected. This prototype has the attribute reflected in all 3 dwelling units of its kind studied -3 out of 3 dwelling units. However this figure (3) is only a negligible percentage $(0.1 \%)$ of the total of 230 dwelling units studied. Therefore, it is the finding of this study that flexibility in space use is not reflected in the architectural designs of the existing public core housing schemes in Anambra State.

Additionally, the core house prototypes studied seem to resemble full provision/ finished houses rather than core houses as can be seen in the results obtained for the variables that make up flexibility in space use in architectural design in relation to core housing affordability and the plans, elevations and photographic images of the prototypes. Considering flexibility in use of sitting room also for dining, for instance, only 3 out of the 230 dwelling units studied have the sitting room serving the dual-function of use for dining. Majority of them were not designed for elastic use of sitting room for dining as well. They have well-structured and dedicated spaces for dining distinct from the sitting room, instead of unstructured spaces that promote dual/multiple space use. In the case of flexibility in use of 
kitchen also for food storage similarly, 22 out of the 230 core housing units studied have the kitchen serving the dual-function of use for a food storage. As such majority of them were not designed for elastic use of kitchen for food storage as well. They have well-structured and dedicated spaces (rooms) for food storage distinct from the kitchen spaces, instead of unstructured ones that promote dual/multiple space use. Considering flexibility in subdivision of some internal spaces after occupation in the same vein, a break-down of the examination shows that all of the 230 core housing units studied have fully-partitioned and finished internal spaces (sitting room, dining, kitchen, bedrooms, toilets) prior to occupation. Hence, the plan of the initial floor areas of the core housing units, have fully-partitioned and finished internal spaces prior to occupation.

\section{DISCUSSION}

In the introductory section of this study, two objectives were set forth to be accomplished. The first concerns a review of flexibility in space use in architectural designs as it relates to affordability of core housing, while the second is on ascertaining if flexibility in space use is reflected in the architectural designs of the existing public core housing schemes in Anambra State. Concerning the first objective, the findings of the study have established what considerations constitute flexibility in space use, namely: (i) flexibility in use of sitting room also for dining; (ii) flexibility in use of kitchen also for food storage; and (iii) flexibility in sub-division of internal spaces after occupation. These characteristics are apt in that each of them essentially assist in promoting the elastic use of spaces which informs flexibility in space use and the functionality of compact spaces. The bulk of literature reviewed show flexibility in space in architectural design as an attribute which makes compact spaces (the core units in this context) work. This is because it provides the enablement for multifunctional use of the initial compact space (core unit) provided. The design of the compact core unit is intended to bring down the house price of the initial habitable unit. By reflecting flexibility in space use in the architectural designs of core houses, affordability is therefore enhanced.

The other objective ascertained if flexibility in space use is reflected in the architectural designs of the existing public core housing schemes in Anambra State. The findings of the study show that flexibility in space use is lacking in their architectural designs. This is contrary to Ike (1996); Napier (2002); Greden (2005); ACSA (2006); Waibel, Eckert and Bose (2007); Gattoni, Goethert and Chavez (2011); Emamgholi (2011), Indrawan, Faqih and Purnomo (2012), Larissa (2013), Adulpader, Sobah and Abdullah (2014) and Esenwein (2016); who highlighted the importance of consideration of dual/multiple space use in the conception of low-cost house prototypes and by extension core house prototypes, because of the potential in making the compact initial unit work. It equally falls short of the Functionalism Theory of Fitness to Purpose in Architecture by Leon Battista that propounds that the proper way to study (design) architecture is to study the uses of buildings and the nature of men for whose use the buildings are intended (Zurko, 1957). The building type under study, core housing relies on the ability of the multi-functinal compact space accommodating the various functions that basically take place in a conventional housing setting. Majority of prototypes were not conceived with the idea of the elastic use of spaces, for example the sitting room and kitchen being designed to cater for dining and food storage repectively also. They rather have well-structured and dedicated dining spaces distinct from 
the sitting rooms, and food stores distinct from the kitchens. This is at the expence of having unstructured spaces that promote dual/multiple space uses and reduced floor space requirements which aids affordability

Considering flexibility in use of sitting room also for food storage, for instance, a good percentage of them were not designed for elastic use of sitting room for dining as well. They have well-structured and dedicated spaces for dining distinct from the sitting rooms, instead of unstructured spaces that promote dual/multiple space use, a consideration which reduces the demand for increased need of floor spaces and aids affordability (Ike, 1996; Emamgholi, 2011; Esenwein, 2016). In the case of flexibility in use of kitchen also for food storage as well, majority of the prototypes have well-structured and dedicated spaces for food storage distinct from the sitting rooms, instead of unstructured spaces that promote dual/multiple space use. The lack of this consideration falls short of the findings of Ike (1996), ACSA (2006) and Adulpader, Sobah and Abdullah (2014) that core house prototypes should have flexible spaces that can be put into optimum usage being unstructured and available for elastic use. The study reckons that this characteristic promotes housing affordability. On the issue of flexibility in sub-division of some internal spaces after occupation the findings show that all prototypes studied have fully - partitioned and finished internal spaces (sitting room, dining, kitchen, bedrooms, toilets) prior to occupation, instead of un-partitioned and unfinished spaces that could be upgraded while in occupation (Napier, 2002; ACSA, 2006).

The deficiency of these conditions have failed to indicate that the prototypes were properly thought out and designed as core houses. This is not surprising since majority of them appear to take the form of full provision/ finished houses, although they are supposed to be core houses. The lack of these design considerations negatively influence the attribute "flexibility in space use in architectural design" and apparently would have affected the affordability of the prototypes for the intended residents.

\section{Implications to Research and Practice}

This study has been able to explain flexibility in space use in architectural design in relation to core housing affordability to incorporate: (i) flexibility in use of sitting room also for dining; (ii) flexibility in use of kitchen also for food storage; and (iii) flexibility in subdivision of internal spaces after occupation. The study has equally substantiated that flexibility in space use in architectural design is one of the attributes that promote core housing affordability. This it does by the enablement for multi-functional use of the initial compact space (core unit) provided such that it works, and thereby eliminating the need of provision of larger space for the initial core house. It was established from this study that the existing public core house prototypes in Anambra State lack flexibility in space use in their designs and that they were conceived more like whole (full-provision/finished) houses rather than core houses. This has added empirical information to the body of knowledge in this area of research and, alongside studies on other design attributes of core housing affordability, would be useful in furthering knowledge on the affordability question. It has provided useful information to housing design professionals in knowing areas and steps to consider in ensuring the inclusion of this attribute in future core housing designs, in search of their affordability. The deficiency in this vital attribute of core housing affordability established in this study may have affected the affordability of these prototypes for the intended residents. This has provided grounds for further studies in order to know the relationship between flexibility in space use in architectural design of core housing schemes and their affordability. 


\section{CONCLUSION}

This study is predicated on the background of the fact that flexibility in space use in architectural design is a crucial attribute for enhancing core housing affordability, and the need to explain what design considerations constitute it. The study further stems from the fact that despite the affordability improvement importance of this attribute, it has not been examined in order to ascertain if it has been properly represented in the designs of existing public core housing schemes. This study was necessary in the study area because dearth of the above information was observed to be seemingly true in Anambra State, Nigeria. It therefore first reviewed relevant literature on flexibility in space use in architectural design in relation to core housing affordability and established the variables that characterized it. It then ascertained the reflection of flexibility in space use in the architectural designs of the existing public core housing schemes in Anambra State.

The findings of the study explained flexibility in space use in architectural design in relation to core housing affordability to incorporate: (i) flexibility in use of sitting room also for dining; (ii) flexibility in use of kitchen also for food storage; and (iii) flexibility in subdivision of internal spaces after occupation and it reaffirmed that this attribute is crucial in fostering affordability of core housing schemes. This study is apt having been able to establish these facts and closing the gap in knowledge. In so doing, it has succeeded in supplying design professionals with information relevant in inculcating this attribute in future core housing designs. The study therefore recommends that due consideration be given to the variables that make up flexibility in space use in architectural design of future core housing schemes in the study area; in order to promote affordability.

\section{REFERENCES}

Abrams, C. (1964). Man's struggle for shelter in an urbanizing world. Cambridge, M. I. T Press, 1-2, 174-181.

Adulpader, Sobal, \& Abdullah , H. (2014). Impact of flexibility principle on the Eeficiency of interior spaces. International Transaction Journal of Management. Retrieved June 10, 2018

Association of Collegiate Schools of Architecture - ACSA. (2006). Affordable design: Convening the conversation. Mae Foundation 3900, Wisconsin Avenues, N.W Washington D.C 2016-2892. Retrieved from https://www.acsa-arch.org/.../affordable

Atamewan, E. E., \& Olagunju, R. E. (2017). Incremental construction for sustainable lowincome housing delivery in developing countries: A case study of Bayelsa State, Nigeria. Journal of Sustainable Architecture and Engineering, 20-38. .

Breimer, T. (2011). Open building as an approach for more effective core housing implimenation? An exploration. Masters Degree Progrmme in Urban Management and Development, Lund University. Retrieved 2011.

Emamgholi, A. (2011). Flexible spaces in architecture, paper presentation. 6th Symposium on Advances in Science and Technology (SASTech). Iran/Mashad.

Esenwein, F. (2016). Simply American: simplicity in Architectural arrangement, construction and standard. published $\mathrm{Ph}$. D Thesis, University of Pennsylvania, U.S.A.

Feins, J. D., \& Lane, T. S. (1981). How much for housing? New perspectives on affordability and risk. Abt Books. 
Gattoni, G., Goethert, R., \& Chavez, R. (2011). Self-help and incremental housing: Likely directions for future policy. Research Report, Universidad Jose Simeon Canas and Universidad de El Salvador.

Goethert, R. (2010). Incremental housing. a pro-active urban strategy. Incremental Housing Bulletin.

Gorglewski, M. (2005). Understanding how buildings evolve. World Sustainable Building Conference, (p. 2811). Tokyo.

Greden, L. (2005). Flexibility in buildings: A real Options approach and valuation methodology.

Greene, M., \& Rojas, E. (2008). Incremental construction: A strategy to facilitate access to housing. Environment and Urbanization, 20(1), 19.

Grimmes, O. (1976). Housing for low-income urban families. The John Hopkins University. World Bank Research Publication.

Gudeta, H. A. (2010). An assessment of urban housing supply and affordability in Jimma Town: with reference to condominium housing. M.A Thesis, Institute of regional and local development studies.

Hancock, K. E. (1993). 'Can pay? Won't pay?' or economic principles of affordability. Urban Studies, 30(1), 127-145..

Ike, E. (1996). Affordable homes: A guide to easy home-building. Lagos: The Show Kemt Ltd.

Indrawan I, Faqih, M., \& Purnomo, H. (2012). Flexibility and adaptability as architectural approach in designing hospitals.

Larissa, A. (2013). Flexible architecture for the dynmic societies: reflections on a journey from the 20th century into the future. Masters Degree Thesis in Arts, Universiy of Tromso, Faculty of Humanities, Social Sciences and Education. Retrieved from munin.uit.no/bitstream/handle/1007/5462/thesis.pdf

Maly, E., \& Tamyo, K. (2012). An incrementally expandable core house for disaster reconstruction: Two cases in Yogyakarta, Indonesia, After the Central Java Earthquake. Memoirs of Graduate School of Engineering and Systems Informatics, 4, pp. 1-7.

Milligan, V. R. (2003). How different? comparing housing policies and housing affordability consequences for low-income households in Australia and the Netherlands. Utrecht, Sydney: Labor Grafimedia b. v.

Mutisya, K. R. (2015). Housing affordability in Kenya: A case Study of the mortgage housing sector in nairobi. School of Built Environment, University of Nairobi, Kenya, Department of Real Estate and Construction Manangement. Retrieved August 2015

Napier, M. (2002). Core housing, enablement and urban poverty: The consolidation paths of households living in two South Saharan African settlement. ph.D Thesis, University of Newcastle upon Tyne. Retrieved 2012, from http:/www.urbanlandmark.org.za

National Population Commision of Nigeria. (2006). National population census of Nigeria, Federal Republic of Nigeria.

Ndubueze, O. J. (2009). Urban housing affordability and housing policy dilemmans in Nigeria. University of Brbaughan. Centre for Urban and Regional Studies, School of Public Policy.

Okoye, N. B. C. D., Onyegiri I., \& Okafor M. (2021). Effect of architectural design characteristics affecting design simplicity on affordability improvement of core housing schemes. Journal of Advanced Research and Multidisciplinary Studies 1(1), 26-34. DOI: $10.52589 / J A R M S 9 P 4 A 2 M 5 S$. 
Pandelaki, E., \& Shiozaki, Y. (2010). The core house concept and its implementation in indonesia, past, present, future. International Journal for Housing Science, 34(44), 233 248. Retrieved 11 12, 2017, from www.housingscience.org/html/publications/pdf/34-42.pdf

Routio, P. (2007). Theories of Architecture.

Schmidt III, R., Eguchi, T., \& Gibb, A. (2010). What is the meaning of aaptability in buiding industry? Loughborough University, United kingdom. Open and Sustainable Building, Chicago..

Sharipah, N., \& Sidi, S. (2011). Quality affordable housing: A theoretical framework for planning and design of quality housing. Journal of Techno-SocialMy Journal-

Malaysian Citation Centre, 1-10. Retrieved from www.myjournal.my/public/issueviewphp?id $=2787 \&$

Ugonabo, C., \& Emoh, F. (2013). The major challenges to housing development and delivery in Anambra State of Nigeria. Civil and Environmental Research Journal, 3(4).

United Nations Human Settlements Programme, UN-HABITAT. (2009). Structural plans for Awka and Satellite Towns. Retrieved November 16, 2017, from http://www.unhabitat.org.

Waibel, M., Eckert, R., \& Bose, M. (2007). Housing for low-income groups in Ho Chi Minh city: between re-integration and fragmentation. Approaches to Adequate Urban Typologies and Spatial Strategies, 70-74.

Zukor, E. R. (1957). Origins of functionalist theory. New York: Columbia University Press. 


\section{APPENDIX A}

\section{OBSERVATION SCHEDULE:}

Objective 1: Examining Flexibility in Space use in Architectural design of the Existing Public Core House Prototypes in Anambra State.

\section{Prototype:}

\begin{tabular}{|c|c|c|c|c|c|}
\hline $\mathbf{S} / \mathbf{N}$ & $\begin{array}{l}\text { Variable } \\
\text { Number }\end{array}$ & Vari & le Description & $\begin{array}{l}\text { Rating } \\
\text { (Status) }\end{array}$ & \\
\hline & & For & General Information & YES & NO \\
\hline
\end{tabular}

Flexibility in space use in Architectural Design

1. V1 Flexibility in use of sitting room also for dining also

2. V2 Flexibility in use of kitchen also for food storage also

3. V3 Flexibility in sub-division of internal spaces after occupation 


\section{APPENDIX B}

\section{INTERVIEW GUIDE: PILOT SURVEY}

Interview with the Head of Estate Management Department, Anambra State Housing Development Corporation, Awka, Anambra State.

Length of Time: 25-30 minutes.

Goal: To obtian knowledge on issues of concern to this research from your point of view, based on your experience.

1. Name:

2. Establishment:

3. Department:

4. Designation:

5. The Anambra State housing provision policy is based on:

(i) Outright purchase of houses

(ii) Sites and services programme

(iii) Mortgage arrangement 


\section{APPENDIX C}

\section{INTERVIEW GUIDE: PILOT SURVEY}

Interview with the Head of Quantity Surveying Department, Anambra State housing Development Corporation, Awka, Anambra State.

Length of Time: $25-40$ minutes.

Goal: To obtain knowledge on issues of concern to this research from your point of view, based on your experience.

1. Name:

2. Establishment:

3. Department:

4. Designation:

5. The land/building costs of 1-bedroom, 2-bedroom and 3-bedroom fullprovision/finished house types within Awka city as at the year 2016?

(i)

(ii)

(iii) 